NBER WORKING PAPER SERIES

\title{
HOW MUCH DOES SIZE ERODE MUTUAL FUND PERFORMANCE? A REGRESSION DISCONTINUITY APPROACH
}

\author{
Jonathan Reuter \\ Eric Zitzewitz \\ Working Paper 16329 \\ http://www.nber.org/papers/w16329 \\ NATIONAL BUREAU OF ECONOMIC RESEARCH \\ 1050 Massachusetts Avenue \\ Cambridge, MA 02138 \\ September 2010
}

We thank Vikas Agarwal (discussant), Jonathan Berk, Joe Chen, Wayne Ferson, Edie Hotchkiss, Jeffrey Pontiff, Laura Starks, Phil Strahan, two anonymous referees, and participants at Babson College, Boston College, Tilburg, the 2009 Financial Research Association annual meeting, and the 2012 Financial Intermediation Research Society conference for helpful comments. Any remaining errors are our own. The views expressed herein are those of the authors and do not necessarily reflect the views of the National Bureau of Economic Research.

NBER working papers are circulated for discussion and comment purposes. They have not been peerreviewed or been subject to the review by the NBER Board of Directors that accompanies official NBER publications.

(C) 2010 by Jonathan Reuter and Eric Zitzewitz. All rights reserved. Short sections of text, not to exceed two paragraphs, may be quoted without explicit permission provided that full credit, including $(\mathcal{C}$ notice, is given to the source. 
How Much Does Size Erode Mutual Fund Performance? A Regression Discontinuity Approach Jonathan Reuter and Eric Zitzewitz

NBER Working Paper No. 16329

September 2010, Revised July 2015

JEL No. G14,G23,G24

\begin{abstract}
$\underline{\text { ABSTRACT }}$
The level of diseconomies of scale in asset management has important implications for tests of manager skill and the expected level of performance persistence. To identify the causal impact of fund size on future returns, we exploit the fact that small differences in returns can cause discrete changes in Morningstar ratings that, in turn, generate discrete differences in size. Despite robust evidence that Morningstar ratings increase fund size, our regression discontinuity estimates yield little evidence that fund size erodes returns. Consequently, any downward bias in standard estimates of performance persistence due to diseconomies of scale is likely to be small.
\end{abstract}

Jonathan Reuter

Carroll School of Management

Boston College

224B Fulton Hall

140 Commonwealth Avenue

Chestnut Hill, MA 02467

and NBER

reuterj@bc.edu

Eric Zitzewitz

Department of Economics

Dartmouth College

6106 Rockefeller Hall

Hanover, NH 03755

and NBER

eric.zitzewitz@dartmouth.edu 
The literature testing for the skilled mutual fund managers is one of the largest in finance. Studies of manager skill are easy to motivate. Actively managed mutual funds hold trillions of dollars in assets and generate billions of dollars in management fees for fund families and their managers. For example, while the market share of equity index funds continues to rise, $79.2 \%$ of the assets invested in equity funds in the U.S. in 2014 were invested in actively managed funds. ${ }^{1}$ At the same time, the oldest branch of this literature continues to raise significant questions about the ability of active fund managers to justify their fees. ${ }^{2}$ Low levels of performance persistence among active funds combined with average risk-adjusted, after-fee returns consistently below those available in index funds has lead some prominent researchers to puzzle over the continued demand for active management (e.g., Gruber (1996) and French (2008)). The essence of their argument is that investors would do well to stop chasing active funds with high past returns (e.g., Chevalier and Ellison (1997) and Sirri and Tufano (1998)), because high past returns are more likely to reflect luck than skill. This argument begs the question of why the majority of mutual fund assets remain actively managed. ${ }^{3}$

Berk and Green (2004) provide an intriguing potential answer based on diseconomies of scale. In their model, rational investors chase performance to the point that expected future returns are equalized across funds. In equilibrium, more-skilled managers manage more assets but - precisely because of the diseconomies of scale associated with managing more assetsearn the same expected future return as their less-skilled peers. In other words, diseconomies of scale can potentially rationalize both the high market share of active funds and low levels of performance persistence. Whether diseconomies of scale play a first-order role in explaining the

\footnotetext{
${ }_{2}^{1}$ See Figure 2.15 in Investment Company Institute's 2015 Fact Book.

2 See, for example, Jensen (1968), Malkiel (1995), Gruber (1996), Carhart (1997), French (2008), and Fama and French (2010).

${ }^{3}$ A relatively new branch of the literature seeks to answer this question by focusing on measures other than riskadjusted, after-fee returns. See, for example, Glode (2011) and Berk and van Binsbergen (2012).
} 
observed levels of performance persistence depends crucially on their magnitude.

Our goal in this paper is to estimate the causal impact of fund size on fund performance, and then revisit estimates of performance persistence. To motivate our empirical strategy, it is helpful to view the existing evidence through the lens of Berk and Green's (2004) model. In a study that is both representative and widely cited, Chen, Hong, Huang, and Kubik (2004, hereafter CHHK) regress mutual fund returns on lagged fund size and other observable fund characteristics. They find that a fund that is a log order of magnitude larger earns risk-adjusted returns that are 2 to 3 basis points per month lower. ${ }^{4}$ If we were to interpret this difference as the causal effect of fund size on returns, we would conclude that diseconomies could not be masking a meaningful amount of performance persistence. First, we know that a fund that outperforms its peers by one percentage point this year will be $2-5$ percentage points larger next year (one percentage point from returns mechanically increasing assets, and the other 1-4 percentage points from the flow-performance relation). ${ }^{5}$ Second, CHHK's estimate implies that a fund that is one percentage point larger will earn returns that are about 0.003 percentage points lower over the next 12 months. Combining these two estimates implies that a fund that outperforms its peers by one percentage point this year will suffer a $0.6-1.5$ basis point penalty next year. In other words, if we interpret CHHK's estimate as an estimate of the causal effect of fund size on performance, the effect described in Berk and Green will cause us to underestimate an annual AR(1) coefficient by 0.006-0.015. Given that we estimate the annual AR(1) coefficient to be approximately 0.1 , the estimated diseconomies of scale in CHHK are too small to meaningfully affect our views about the level of return persistence.

\footnotetext{
${ }^{4}$ Chen, Hong, Jiang, and Kubik (2013) and Massa, Reuter, and Zitzewitz (2010) estimate similar partial correlations between fund size and fund returns, although neither paper is focused on the relation between fund size and returns.

${ }^{5}$ We take our range from the graphs of the inflow-performance relationship for the "young" ( $<2$ years) and "old" (>10 years) funds in Chevalier and Ellison (1997), but these slopes have been replicated in many other studies.
} 
However, if fund size is endogenously related to expected future returns, in equilibrium, fund size will be uncorrelated with future returns, thereby frustrating standard approaches to estimating diseconomies of scale. Even if we allow for the possibility that fund sizes are out of equilibrium, the estimates in CHHK (and other studies) will underestimate the actual diseconomies of scale if larger funds have more-skilled managers. ${ }^{6,7}$ In other words, unless the correlation between fund size and manager skill is zero, standard OLS estimates of diseconomies of scale and performance persistence will be biased downward. ${ }^{8}$ The interpretation of OLS regressions of future returns on fund characteristics such as portfolio concentration (Kacperczyk, Sialm, and Zheng (2005)), return gap (Kacperczyk, Sialm, and Zheng (2008)), active share (Cremers and Petajisto (2009)), and $\mathrm{R}^{2}$ (Amihud and Goyenko (2013)) are also likely to be complicated, at least when used to learn about the return production process.

To identify diseconomies of scale in asset management, separately from the effects of other factors that covary with size, we require a natural experiment - something that causes an increase in fund size for reasons that are related to future returns only through diseconomies of scale. We identify such an experiment using a regression discontinuity approach. Our insight is that small changes in fund returns can have discontinuous impacts on fund flows through their

\footnotetext{
${ }^{6}$ When testing for diseconomies of scale, Elton, Gruber, and Blake (2012) assert that "if Berk and Green (2004) are right, then we should find no predictability among big funds for which diseconomies of scale are more likely to be important" (p. 34). This implicitly assumes that the correlation between manager skill and fund size is zero (or only weakly positive), whereas the correlation is strongly positive within the Berk-Green model.

${ }^{7}$ Controlling for additional fund characteristics, as is common in studies comparing large and small funds, does not change the fundamental prediction that the partial correlation between fund size and expected returns should be zero, even in the presence of scale diseconomies. When observable fund characteristics impact expected returns, investors should allocate dollars across funds such that expected returns are equal conditional on those characteristics.

${ }^{8}$ Edelen, Evans, and Kadlec (2007) and Yan (2008) provide evidence that trading costs are higher in larger funds, likely depressing returns. If larger funds have more skilled managers, and skill mitigates trading costs, the partial correlation should yield a conservative estimate of the causal effect of size on trading costs. Gutierrez, Maxwell, and $\mathrm{Xu}$ (2009) find no evidence of a size-return correlation for bond funds, and suggest that differences in sizereturn correlation between stock funds and bond funds reflects differences in economies of scale in trading costs for stocks and bonds. Alternatively, size-skill relationship may stronger for bond funds, where skill may be more important or more readily inferred by investors from fund returns.
} 
impact on the fund's Morningstar rating. For example, as a fund's within-category Morningstar performance ranking increases from the $89^{\text {th }}$ percentile to the $90^{\text {th }}$ percentile, its Morningstar rating increases from four stars to five stars. Under the assumption that manager skill varies continuously across each of the Morningstar rating thresholds, we can use high frequency data on Morningstar performance rankings to identify the casual impact of Morningstar rating thresholds on fund inflows. Then, because this source of fund inflows is uncorrelated with manager skill (and other factors affecting future returns), we can use these inflows to identify the causal impact of fund size on fund performance. In other words, we are using small deviations from the rational behavior assumed in the Berk-Green model to measure the extent of diseconomies of scale.

We have four main empirical findings, based on monthly data from Morningstar that covers virtually every mutual fund in operation between December 1996 and August 2009. First, in our first-stage regressions, we show that mutual funds just above the threshold for a Morningstar rating receive incremental net flows over the next six months that are equal to approximately 2.5 percent of assets under management. Second, looking out over the next 6-24 months, we find little evidence of diseconomies of scale. Our reduced-form estimates of the impact of incremental net flows on returns are largely positive during the first six months and largely negative during the subsequent eighteen months, but none of the estimates are statistically different from zero. In other words, within the full sample of funds, the exogenous variation in fund size that we exploit has little impact on fund returns. ${ }^{9}$

Third, when we shift our focus to subsamples based on investment objectives (e.g., smallcap equity funds or sector funds), we continue to find little evidence of diseconomies of scale.

\footnotetext{
${ }^{9}$ Using an empirical strategy based on fund fixed effects, Pastor, Stambaugh, and Taylor (2014) find statistically significant evidence of decreasing returns to scale at the mutual fund industry level. While their fund-level estimates are negative, they are not statistically significant. Industry-level scale diseconomies may help explain low average risk-adjusted returns, but they would not affect performance persistence coefficients. This motivates our interest in fund-level diseconomies.
} 
For example, despite the fact that incremental inflows into sector funds reach 14.0 percentage points by month 24 , and despite the fact that sector funds should be an ideal category in which to test for diseconomies of scale, we cannot reject the hypothesis that the diseconomies implied by the ratio of our reduced form and first-stage regression coefficients (the Wald estimator) equal those obtained via standard OLS regressions. The only subsamples for which we can reject the hypothesis that the Wald estimate equals the OLS estimate are mid-cap equity funds and municipal bond funds. ${ }^{10}$ Moreover, within both of those subsamples, our Wald estimates imply (small) positive economies of scale.

Finally, we adjust standard OLS estimates of performance persistence for potential diseconomies of scale. Because we find little evidence of diseconomies of scale, our median corrected $\operatorname{AR}(1)$ estimate of 0.088 is virtually identical to our uncorrected estimate of 0.090 . Moreover, the upper bound of the $95 \%$ confidence interval for the corrected persistence coefficient is 0.14 in the full sample of funds, and even lower in some subsamples. ${ }^{11}$ Overall, the diseconomies of scale that we estimated using our regression discontinuity approach are too small to rationalize the low levels of performance persistence among actively managed funds.

\section{Morningstar Ratings and Fund Characteristics}

Our identification strategy relies on the discrete nature of Morningstar ratings. It also relies on the fact that, because Morningstar ratings are based on past returns, we can identify funds near rating thresholds. In this section, we describe how Morningstar ratings are determined. We then

\footnotetext{
${ }^{10}$ One might argue that when OLS and IV estimates are equal, there is no scientific contribution from having done the IV. We disagree, particularly when there is a plausible alternative explanation for the OLS result that the IV approach rules out. Two famous examples come from the literatures on smoking and lung cancer (e.g., Doll (1998)) and wages and education (e.g., Card (1999)). In both cases, initial correlative evidence was dismissed on the grounds that there were very plausible confounding factors, and it was left to later work to establish a causal relationship.

${ }^{11}$ By way of comparison, our estimate of 0.14 is significantly lower than the 0.42 implied by the calibration exercise in Berk and Green. Farnsworth (2013, footnote 2) critiques their calibration exercise on different grounds.
} 
describe our sample.

\section{A. Morningstar Ratings}

Morningstar rates mutual fund share classes on a scale that ranges from one star (the lowest possible rating) to five stars (the highest possible rating). The rating assigned to each mutual fund share class depends on its relative performance within its Morningstar-determined investment category over the prior 3 years, 5 years, and 10 years, "after adjusting for risk and accounting for all sales charges." ${ }^{12}$ Morningstar does not rate mutual fund share classes that are less than three years old.

For mutual fund share classes between the age of three and five years, the Morningstar rating depends entirely on its relative performance over the prior 36 months. "Within each Morningstar Category, the top $10 \%$ of funds receive five stars, the next $22.5 \%$ four stars, the middle $35 \%$ three stars, the next $22.5 \%$ two stars, and the bottom $10 \%$ receive one star." 13 Therefore, small differences in past returns, such as going from the $10^{\text {th }}$ percentile to the $11^{\text {th }}$ percentile, or from the $89^{\text {th }}$ percentile to the $90^{\text {th }}$ percentile, result in discrete changes in Morningstar ratings. These discrete changes are evident in Figure 1, in which we plot Morningstar ratings for all share classes that are less than 5 years old against Morningstar's risk-adjusted, within category return percentile. Figure 1 also provides graphical evidence that (residual) flows increase sharply

\footnotetext{
${ }^{12}$ Morningstar changed various detailed of its ratings process in June 2002. See Blume (1998) for a description of the rating system used from 1996-2002 and http:/quicktake.morningstar.com/DataDefs/FundRatingsAndRisk.html (last accessed 6/30/2015) for Morningstar's description of their current ratings process. The most significant change was that the number of Morningstar Categories used for ratings increased from four on May 2002 (Domestic Equity, International Equity, Taxable Bonds, and Municipal Bonds) to 48 on June 2002, eventually growing to 81 in August 2009. The new Morningstar Categories better reflect actual investment styles (e.g., distinguishing domestic equity funds that focus on large-cap growth from those that focus on small-cap value). Morningstar also changed the method used to risk-adjusting returns, and made the relative importance of 5 and 10-year returns depend on whether a fund had experienced style drift.

${ }^{13}$ See http://quicktake.morningstar.com/DataDefs/FundRatingsAndRisk.html (last accessed 6/30/2015).
} 
around ratings thresholds. ${ }^{14}$ (We present more formal evidence in Section III.)

For share classes between the age of 5 and 10, Morningstar determines separate ratings based on the prior 36 months and the prior 60 months, and "averages" the underlying ratings to calculate an overall integer rating. In Figure 2, we show how relative performance over the prior 36 and 60 months maps into a share classes' overall rating. The pattern reveals that Morningstar calculates a fund's overall rating as a $60-40$ average of the 5-year and 3-year integer ratings, causing it to "round up" when the better performance is over the longer horizon. ${ }^{15}$ For example, a share class with a 36-month return that puts it at the $89^{\text {th }}$ percentile (four stars) and a 60-month return that puts it at the $90^{\text {th }}$ percentile (five stars), receives an overall rating of five stars. In contrast, a share class with a 36-month return that puts it at the $90^{\text {th }}$ percentile (five stars) and a $60-$ month return that puts it at the $89^{\text {th }}$ percentile (four stars), receives an overall rating of four stars. To the extent that we are willing to assume that the managers of these two funds are similarly skilled (conditional on current assets under management) and that the five-star fund receives higher residual flows, we can study the impact of these incremental flows on future returns.

While the staircase boundaries between overall ratings may strike readers as an unusual methodological choice by Morningstar, it is helpful from the perspective of our research, since this approach increases the number of funds that are very close to a rating boundary. For share classes that are more than 10 years old, Morningstar's overall rating depends on the average of the 3-year, 5-year, and 10-year ratings. For these share classes, thresholds between ratings are conceptually similar to those in Figure 2. However, because these thresholds relate to three un-

\footnotetext{
${ }^{14}$ The residual flows in Figure 1 come from versions of the baseline flow regression in Section III that omit the Morningstar within-category percentile ranking and discontinuity dummy variable.

${ }^{15}$ After June 2002, Morningstar began giving older history less weight when funds had experienced style drift. To make Figure 2 more transparent, we exclude these funds from the picture. Depending on how much style drift was experienced and when it was experienced, a fund's 3-year history can receive more than 50 percent of the weight, causing the rounding to occur in the other direction.
} 
derlying ratings, they must be plotted in three dimensions.

\section{B. Sample Construction}

To study the impact of mutual fund flows on mutual fund returns, we obtain data from Morningstar Principia CDs. Our sample consists of all open-end mutual funds that have at least one share class rated by Morningstar. Because Morningstar does not rate share classes that are less than three years old, mutual funds enter our sample when their oldest share class reaches three years of age. The fact that we only study funds in the time period in which they appear on a Morningstar CD limits the influence of incubation bias (Evans (2010)) on our results. While incubation bias might help to explain why funds appearing on a Morningstar CD for the first time have average Morningstar ratings about a quarter point above older funds, our analysis of future inflows and performance uses only non-backfilled data. Consequently, our estimates of scale diseconomies should be unaffected by incubation bias.

Our data begin in December 1996 and end in August 2009. ${ }^{16}$ Because mutual fund share classes can earn different Morningstar ratings and experience different inflows, the unit of observation in our initial analysis of inflows is the share class. As any scale diseconomies would occur at the fund (portfolio) level, however, in most of our analysis we aggregate variables to the fund level, weighting each share class in proportion to its assets under management in the prior month. In practice, the exact approach we take to weighting share classes has little influence on the results because the average fund gets 84 percent of its assets from its largest share class.

Finally, because Morningstar within-category percentile rankings do not distinguish between actively and passively managed mutual funds, we include the share classes of index funds

\footnotetext{
${ }^{16}$ We have been unable to obtain data for 12 of the 36 months between January 1997 and December 1999 . The missing months are January 1997, February 1997, April 1997, May 1997, July 1997, August 1997, October 1997, November 1997, January 1998, July 1998, January 1999, and November 1999. The fact that we have data for all months that end a calendar quarter motivates our focus on time horizons divisible by three months.
} 
in our sample when calculating within-category percentile rankings. However, we are careful to exclude index funds from all inflow and return regressions.

\section{Summary Statistics}

In Table 1, we report fund-level summary statistics for the full sample of 491,863 fund-month observations. We also use asset-weighted average Morningstar ratings to assign fund-level ratings, and report summary statistics for each fund-level rating category. Looking across these categories, we see that funds with higher ratings tend to be larger and come from larger families. Funds with higher ratings also tend to charge lower average fees (both in month $t$ and month $t+12$ ), tend to offer fewer share classes, and are less likely to charge a sales load. Of course, differences in fees and sales loads follow, at least in part, from the fact that Morningstar ratings are based on returns measured net of fees and loads. Although Guedj and Papastaikoudi (2003) find that families can increase fund performance by allocating an additional manager to the fund, and changes in the future allocation of managers to funds in response to crossing a ratings threshold pose a potential challenge to our identification strategy, we find that the number of named fund managers is effectively constant across the five ratings and highly persistent. ${ }^{17}$

The most interesting differences between funds with higher and lower ratings involve future flows and future returns. Consistent with investors responding to Morningstar ratings (or to the return histories underlying them), we find that funds with higher ratings receive higher net flows over the next 24 months. Relative to other funds in their Morningstar category, the typical five-star funds grows by 23 percentage points over this period, while the typical one-star funds shrinks by 18 percentage points. The results presented later imply that of this 41 percentage point difference, about 9 percentage point represents a causal effect of the difference in Morningstar

\footnotetext{
${ }^{17}$ In Appendix Table A1, we test for, but do not detect, discontinuities with respect to current and future changes in management structure.
} 
ratings on flows, with the remainder being due to investors responding directly to observable fund characteristics included in Morningstar's ratings (e.g., past returns, risk, and loads), other observable characteristics correlated with the ratings (e.g., low expenses), or unobservable characteristics correlated with the ratings (e.g., marketing efforts). ${ }^{18}$

Consistent with prior work on the predictive power of Morningstar ratings (e.g., Blake and Morey (2009)), we find that one-star funds underperform other funds over the next 24 months, but find little difference in the future performance of other funds. The fact that 5 -star and 2-star funds perform approximately as well in the future despite 5-star funds experiencing greater inflows does not necessarily imply the absence of scale diseconomies, however. In the Berk-Green model, the 5-star funds attract more inflows because they have more skilled managers, and this skill allows the funds to match the 2-star funds' returns despite managing more assets. For a test for scale diseconomies to be valid, it needs to exploit a source of variation in inflows that is not caused by or correlated with manager skill. Fortunately, the discontinuities in the Morningstar ranking function generate this type of variation.

\section{Overview of RD and our Identification Strategy}

In order to measure the causal impact of fund size on fund performance, we must identify variation in fund size that is uncorrelated with manager skill. In markets with perfectly rational, informed investors, this variation should be impossible to come by. We use a regression discontinuity approach that exploits the fact that mutual funds with past returns immediately above a Morningstar rating threshold receive a discretely higher rating than mutual funds with past re-

\footnotetext{
18 Prior work examining the relationship between fund inflows and Morningstar ratings uses observable variables to control for these factors. For example, when they include fund fixed effects, Del Guercio and Tkac (2008) continue to find a positive association between stars and flows. A limitation of this approach is that fund fixed effects are necessarily assumed to be constant, whereas one might expect some unobservable characteristics (e.g., marketing efforts) to change.
} 
turns immediately below the threshold. To the extent that investors place positive weight on Morningstar ratings, funds with risk-adjusted returns immediately above a ratings threshold are likely to receive significantly more inflows than funds with risk-adjusted returns immediately below the threshold. ${ }^{19}$

Our analysis proceeds in two stages. In the first-stage regressions, we estimate the impact of rating thresholds on future flows. Then, we use reduced-form regressions to estimate the impact of rating thresholds on future returns. The identifying assumption is that while inflow will vary sharply at each threshold, the other fund characteristics that might be related to future returns will vary continuously. ${ }^{20}$ Under this assumption, our first-stage and reduced-form estimates allow us to measure the extent of diseconomies of scale.

More formally, our analysis focuses on actively managed mutual funds just above and below each rating threshold. For example, with respect to the threshold between four stars and five stars, our first-stage regression predicts log net flows as function of the within-category percentile ranking used to determine Morningstar ratings, a dummy variable that indicates whether the within-category percentile ranking the share class $i$ of fund $j$ in month $t$ is above the five star rating threshold, and controls, including multiple controls for past performance and past flows.

$$
\text { Flow }_{i, j, t+1}=\delta_{1 \mathrm{st}} \text { threshold indicator }_{i, j, t}+\lambda \text { ranking }_{i, j, t}+\beta_{1 \mathrm{st}} X_{i, j, t}+\eta_{i, j, t}
$$

\footnotetext{
${ }^{19}$ In the Berk-Green model, investors use risk-adjusted past returns to directly infer manager skill. Because perfectly informed investors will not place any weight on Morningstar ratings, flows will vary continuously across Morningstar rating thresholds. To motivate our RD approach, consider a version of the Berk-Green model where many investors observe Morningstar stars rather than risk-adjusted returns, and make inferences about manager skill based on the average characteristics of funds with that rating. In this version of the model, average performance will be equalized across the different Morningstar ratings. However, there will be flow discontinuities at rating boundaries and - because funds just over a boundary will have similar managerial skill to those just under it — the incremental flows will cause funds just over a boundary to underperform. Of course, given this underperformance, sophisticated investors who directly observe returns will rationally choose to invest in funds just below ratings boundaries. Therefore, for the flow discontinuities that we observe in the data to exist, the number of sophisticated investors must be limited.

${ }^{20}$ Imbens and Lemieux (2008) and Lee and Lemieux (2009) provide excellent overviews of the regression discontinuity approach.
} 
where $\delta_{1 \text { st }}$ measures the discontinuous flow effect associated with the ratings threshold. ${ }^{21}$

In many RD settings, the "forcing variable", which determines whether an observation is above or below the threshold, is exogenous. ${ }^{22}$ In our setting, the forcing variable is the withincategory percentile ranking, which is not exogenous. However, our identifying assumption is that, because all managers are trying to maximize relative performance, manager skill will vary continuously across the threshold for a higher rating. In other words, while we allow for the possibility that managers with slightly higher returns are slightly more skilled, our identification strategy assumes that skill does not jump in a discontinuous way at the threshold between ratings. The fact that thresholds for different Morningstar ratings depend on within-category performance rankings over as many as three investment horizons increases our confidence that the distribution of manager skill is smoother than the distribution of Morningstar ratings. ${ }^{23}$

To estimate fund-level flows, we focus on the discontinuity measure for the fund's largest share class. Then, we estimate a reduced-form regression

$$
\operatorname{Return}_{i, j, t+1}=\delta_{\mathrm{rf}} \text { threshold indicator }_{i, j, t}+\lambda \operatorname{ranking}_{i, j, t}+\beta_{\mathrm{rf}} X_{i, j, t}+\eta_{i, j, t}
$$

where $\delta_{\text {rf }}$ measures the causal effect of ratings thresholds on returns. Under the assumption that the causal effect of ratings thresholds on flows is unrelated to differences in manager skill, $\delta_{\mathrm{rf}}$ will capture any diseconomies of scale associated with these flows. Finally, we can estimate the causal impact of flows (i.e., the treatment) on returns (i.e., the outcome) as the ratio of $\delta_{\mathrm{rf}}$ to $\delta_{1 \mathrm{st}}$.

\footnotetext{
${ }^{21}$ Following the advice in Imbens and Lemieux (2008), we experimented with more flexible approaches to controlling for the ranking variable, but found that the results varied little from the local linear approach.

${ }^{22}$ For example, to study the impact of the Sarbanes-Oxley Act on firms costs and earnings, Iliev (2010) exploits the fact that U.S. firms with a public float below $\$ 75$ million in 2002, 2003, or 2004 were allowed to delay compliance with Section 404 until well after the November 2004 date on which slightly larger firms were required to comply.

23 An common concern in regression discontinuity studies is manipulation of the forcing variable. In our setting, the forcing variables is the within-category percentile ranking, so our identification approach would be threatened if funds with more skilled managers were also able to manipulate their returns in order to place just above a Morningstar cutoff. We conduct several tests for and find no evidence of such manipulation. We test for discontinuities in the density of risk-adjusted returns around Morningstar cutoffs (McCrary (2008)) and for month-to-month persistence in the discontinuity variable (controlling for the forcing variable). We also test for discontinuities in lagged flows and returns and the control variables. These results are presented in an Appendix.
} 
The more negative the Wald estimator, the larger the implied diseconomies of scale.

\section{Impact of Morningstar Ratings on Flows}

In this section, we present evidence that Morningstar ratings have a causal impact on investor flows. Because our identification strategy exploits the discreteness of Morningstar ratings, and because different share classes of the same mutual fund can receive different Morningstar ratings, we begin by studying the impact of Morningstar ratings on net flows at the share class level. Consistent with equation (1), our general approach is to regress log net flows of share class $i$ in month $t+1$ on its Morningstar percentile ranking in month $t$, which is our local linear control, and a dummy variable that indicates whether share class $i$ is above the threshold for a particular rating in month $t$. Under the assumption that manager skill varies continuously across the rating threshold, the dummy variable will capture incremental flows into the higher-rated fund that are uncorrelated with manager skill.

To quantify these discontinuous flow effects, in Table 2, we estimate separate regressions for each rating thresholds (i.e. one star versus two stars, ..., four stars versus five stars), and a pooled regression that combines all four thresholds. In each case, the sample is restricted to those share classes that are within five percentiles of a rating threshold. ${ }^{24}$ For example, when we focus on the threshold between four and five stars, we restrict the sample to share classes with Morningstar rankings between the $85^{\text {th }}$ and $95^{\text {th }}$ percentiles. We further restrict the sample to actively managed funds by excluding any fund that Morningstar identifies as an index fund.

In addition to the variables that we report in Table 2, "Baseline" regressions control for the lagged log size of the share class, portfolio, and family, portfolio turnover, expense ratio, and

\footnotetext{
${ }^{24}$ In the Appendix, we present robustness checks that vary this five percentile bandwidth.
} 
the presence of loads (front, deferred, and trailing). ${ }^{25}$ Because our sample includes the full range of Morningstar categories (i.e., large-cap equity, sector funds, corporate bond funds, etc.), we include a separate fixed effect for each Morningstar category each month. This allows us to compare funds to their peers. ${ }^{26}$ In the regressions with "Additional Controls", we supplement the Morningstar percentile ranking variable with controls for Morningstar's measure of risk-adjusted returns, lagged log returns from $t-12$ to $t-1, t-24$ to $t-13$, and $t-36$ to $t-25$, and lagged log inflows from $t-12$ to $t-1$ and $t-3$ to $t-1$. Because mutual funds with multiple share classes can appear multiple times in the same month, we cluster standard errors on the fund. ${ }^{27}$

The estimated coefficients on the threshold indicator variable are positive and statistically significant for each of the four ratings thresholds, and for the pooled regression that includes all four ratings thresholds. In the baseline regressions, the estimates range from 0.337 percentage points at the boundary between 1 star and 2 stars (significant at the 5-percent level) to 0.946 percentage points at the boundary between 4 stars and 5 stars (significant at the 1-percent level). When we include additional controls for past returns and past flows, the estimated coefficients decline, but only slightly. For example, within the stacked regression, the estimated coefficient falls from 0.518 to 0.432 percentage points, but remains statistically significant at the 1-percent level. In other words, share classes that are just above the Morningstar ratings threshold this

\footnotetext{
${ }^{25}$ Edelen (1999) finds that investor flow volatility is associated with lower fund returns and higher trading activity. The incremental net flow caused by Morningstar ratings may be accompanied by higher gross flow that stimulates trading. While we lack Edelen's hand-collected data on gross flows, we do not find evidence of discontinuities in future portfolio turnover at Morningstar boundaries, and including portfolio turnover as a control does not materially affect our results.

${ }^{26}$ Pastor and Stambaugh (2012) hypothesize and Pastor, Stambaugh, and Taylor (2014) conclude that there are diseconomies of scale at the mutual fund industry level. Including category-by-month fixed effects effectively controls for changes in the average return each month due to changes in the intensity of competition.

${ }^{27}$ Given the large number of regressions estimated in the study and the large number of category-time fixed effects included in each model, it is not practical to cluster standard errors on both fund and month (e.g., following Petersen (2009)). However, when we experimented with two-way clustering on fund and month, we found that the standard errors were quite similar to those reported in the paper. This is likely because all of our regressions include time fixed effects and because the distribution of Morningstar ratings is stable across time periods. We also found that our results were robust to clustering standard errors by family instead of by fund.
} 
month receive an additional 0.432 percentage points in net flow next month, compared to share classes that are just below the threshold.

Our identifying assumption is that manager skill and other fund characteristics related to future returns vary continuously across rating thresholds. In the last two columns of Table 2, we test this assumption by changing the dependent variable from log net flows in month $t+1$ to $\log$ net flows in month $t$. If the discontinuity in flows in month $t+1$ is due to a discontinuity in flowproducing (and, potentially, return-producing) fund characteristics at the start of month $t$, rather than to the higher Morningstar rating, we should also find discontinuity effects in month $t$. Importantly for our empirical strategy, when we shift our focus to current-month flows, only five of the ten estimated coefficients on the discontinuity dummy variable are positive, and only one is statistically significant from zero (at the 10-percent level). These results strongly suggest that the discontinuity in flows in month $t+1$ is solely due to the higher Morningstar rating. Overall, the results in Table 2 provide the "first stage" that we need to study the causal impact of flows on performance.

Of course, to test for diseconomies of scale, we need to study the impact of fund-level flows on fund-level performance. In Table 3, we study the impact of Morningstar ratings on log net flows at the fund level. Because many funds have more than one share class, we need a measure of incremental flows that is aggregated across all of fund $j$ 's share classes. Most funds have a main share class that contains the majority of the assets (traditionally the "A" class for load funds and the "Investor" class for no-load funds). Because other share classes have the same return gross of fees and expenses, within-fund differences in returns (and Morningstar percentile rankings) reflect differences in fees and expenses. The Morningstar rating of the largest share class is generally the one marketed to potential investors, as other share classes either have lower 
ratings due to higher fees (e.g., B, C, and Service share classes) or impose restrictions on who can purchase them (e.g., Institutional share classes). Our approach is to focus on the discontinuity and ranking variables for fund $j$ 's largest share class. ${ }^{28}$

The estimated coefficients in the first two columns of Table 3 are qualitatively similar to those in Table 2, with slightly smaller magnitudes because the denominator is fund-level assets rather than share class-level assets. Seven of the ten coefficients are statistically significantly different from zero at conventional levels, with the lack of a discontinuity at the $1 / 2$ star boundary being the major exception. Importantly, we continue to find little evidence of a discontinuity in current month flows.

Again, the coefficient estimates from the regressions with additional controls are slightly smaller than the baseline estimates, but the differences are never statistically significant. Because we find the strongest evidence of flow discontinuities when we stack the $3 / 4$ star and $4 / 5$ star boundaries, we focus on these boundaries in later tables. Figure 3 provides graphical evidence of the discontinuity in future inflows at each rating threshold. ${ }^{29}$ Figure 4 provides graphical evidence of the lack of the discontinuity in current month inflows. In the appendix, we provide evidence of a lack of discontinuities in the control variables, which further supports our identification strategy.

\section{Testing for Diseconomies of Scale}

We now use the incremental flows earned by funds with returns just above rating thresholds to test for diseconomies of scale. We begin by estimating first-stage and reduced-form regressions on the full sample of mutual funds over longer investment horizons. Then, because diseconomies

\footnotetext{
${ }^{28}$ As an alternative, we experimented with taking the highest Morningstar rating and ranking variable across all share classes, on the assumption that this would be the rating marketed to investors. We found very similar results.

${ }^{29}$ Residual flows in Figures 3 and 4 are estimated from the baseline specification in Table 3 but omit the Morningstar within-category percentile ranking and discontinuity dummy variables.
} 
of scale may differ across asset classes, we estimate first-stage and reduced-form regressions for different subsamples of mutual funds. Finally, we compare the diseconomies of scale estimates implied by our first-stage and reduced-form regressions to the diseconomies of scale estimates implied by standard OLS regressions.

\section{A. Evidence from Broad Samples of Equity and Bond Mutual Funds}

In Table 4, we extend the analysis in Table 3 along three dimensions. First, rather than estimating first-stage regressions focused on log net flows in month $t+1$, we estimate first-stage regressions focused on cumulative log net flows over different investment horizons. Our goal is to measure the long-term impact of rating thresholds on fund flows. Second, for each first-stage regression of log net flows on the discontinuity variable (and full set of controls), we estimate an analogous reduced-form regression of log net returns on the discontinuity variable (and same set of controls). Given our identification assumption that flows associated with rating thresholds are uncorrelated with manager skill, these flows should only impact fund returns through diseconomies of scale. The reduced-form regressions are intended to measure this impact. Third, in addition to reporting regression results for the full sample of actively managed funds ("All funds"), we report results separately for equity funds ("All equity") and bond funds ("All bonds"). We focus on specifications where the $3 / 4$ star and $4 / 5$ star boundaries are stacked, and report results for specifications that use other boundaries in the Appendix. Standard errors are clustered on fund.

When we restrict attention to net flows in $t+1$ and net returns in month $t+1$, we find little evidence of diseconomies of scale. Estimated incremental flows are between 0.56 and 0.59 percentage points, depending on the sample that we study, and statistically significant from zero at the 5-percent level and below. In contrast, the estimated coefficients on the threshold indicator 
variable in the return regression are economically small, ranging between -0.01 and 0.01 percentage points, and are not statistically significantly different from zero at conventional levels.

When we focus on cumulative log net flows beyond month $t+1$, we continue to find that Morningstar rating boundaries are associated with significant incremental flows. For example, in the "All funds" sample, the incremental flows associated with the threshold indicator variable (measured in month $t$ ) are 0.59 percentage points in month $t+1,1.75$ percentage points through month $t+6,2.34$ percentage points through month $t+12$, and 2.88 percentage points through months $t+24$. These estimates imply that while the effect of an extra Morningstar star in the ranking disseminated during month $t+1$ is strongest in that month, the effect of the extra star persists beyond the initial month. There are numerous mechanisms that could produce this effect. Investors may make an initial investment in month $t+1$ based on the current-month Morningstar rating, and that initial investment decision may affect the placement of subsequent investments. Investors may also make investment decisions based on an accumulation of signals received over several months. Regardless of the mechanism, our findings about the timing of investor reactions to Morningstar are consistent with prior findings on the timing of investor reactions to media mentions or advertising (e.g., Reuter and Zitzewitz (2006)).

When we examine returns after month $t+1$, we continue to find little evidence that the variation in fund size associated with rating thresholds affects future returns. Through month $t+6$, the coefficients on the threshold indicator variable are almost uniformly small and positive, possibly reflecting the finding in Lou (2012) that flows can temporarily push up security prices. The strongest evidence of scale diseconomies appears in month $t+18$, where equity funds with returns just above a rating threshold receive flows totally 2.62 percentage points of assets and underperform their peers by 5 basis points. However, the underperformance is not statistically 
significant at conventional levels. Moreover, none of the return effects for bonds after month $t+2$ is negative. In other words, exploiting exogenous variation in fund size due to Morningstar rating thresholds, we find little evidence of diseconomies of scale. In Figures 5A, 5B, 6A, and $6 \mathrm{~B}$, we graph the contemporaneous and cumulative flow and return effects for equity and bond funds as a function of time.

\section{B. Evidence from Different Investment Categories}

Although we find little evidence of diseconomies of scale within broad sample of mutual funds, we might reasonably expect the degree of diseconomies of scale to vary across asset classes. For example, CHHK find their strongest evidence of diseconomies of scale among small-cap equity funds. More generally, we might expect the strongest diseconomies of scale in asset classes with less liquidity (e.g., municipal bond funds) or where the inflows experienced by a typical fund are large relative to the investment options available (e.g., sector funds).

In Table 5, we re-estimate the first-stage and reduced-form regressions for different mutual fund categories over four different investment horizons. We use the Morningstar category variable to create the following seven non-overlapping subsamples of mutual funds: large-cap equity; mid-cap equity; small-cap equity; sector funds; international equity; taxable bonds; municipal bonds. (We exclude a small set of funds that do not fall into these categories, such as balanced funds, commodities funds, and target-date retirement funds.) The "All equity" sample that we introduced in Table 4 combines large-cap equity, mid-cap equity, small-cap equity, sector funds, and international equity. The "All bonds" sample includes "taxable bonds" and "municipal bonds." We focus on cumulative log flows and $\log$ returns through month $t+6, t+12, t+18$, and $t+24$.

The estimated flow and return effects in the first column of Table 5 are for all funds, all 
equity, and all bonds and match those reported in Table 4 . The other columns focus on different types of funds. Looking across the seven non-overlapping subsamples, we see that the estimated flow effects are almost always positive, but also that the standard errors tend to be much larger than in the full sample. The evidence that Morningstar rating thresholds impact flows is strongest for sector funds, taxable bond funds, and municipal bond funds. For sector funds, the magnitudes are quite large, ranging from 5.91 percentage points in month $t+6$ to 13.71 percentage points in month $t+24$. Given our need to focus on exogenous variation in fund size, it is hard to imagine ever finding exogenous variation in fund size beyond 13.71 percentage points. The only subsample-horizon first-stage estimates that are negative for small-cap equity funds are for months $t+12$ through $t+24$.

Turning to the reduced-form regressions for the seven non-overlapping subsamples, we see that 15 of the 28 estimated coefficients are negative. However, the only negative coefficient that is statistically different from zero at conventional levels is for small-cap equity in month $\mathrm{t}+18$, when the first-stage estimate is also negative (but statistically insignificant). Despite strong flow effects, none of the return effects for sector funds is statistically significant. In contrast, seven of the eight estimates for mid-cap equity and municipal bonds are positive and statistically significant from zero (at the 5-percent level). Overall, the evidence appears to be as consistent with positive economies of scale as with diseconomies of scale.

\section{Evidence from Different Levels of Aggregation}

Above, when we ask how flow and return effects vary across asset classes, the unit of observation is the mutual fund. In this section, we ask how flow and return effects vary across more highly aggregated portfolios. There are two ways to motivate this exercise. ${ }^{30}$ The first is uncertainty about the nature of the diseconomies of scale. As Berk and Green (2004) note, a fund may

\footnotetext{
${ }^{30} \mathrm{We}$ thank the two anonymous referees for encouraging us to perform the analysis in this section.
} 
generate lower returns when it grows "sufficiently large" either because "a manager will spread his information processing activities too thin" (unit of observation should be the manager or management team) or because "large trades will be associated with a larger price impact and higher execution costs" (unit of observation should be the fund or all funds in the family in the same asset class) (p. 1273). The second motivation is to address concerns that the fund-level tests for diseconomies of scale are confounded by the reallocation of resources (or crosssubsidization) within fund families.

We report versions of Table 5 for four different levels of aggregation in the Appendix. (See Tables A4 through A7.) Regressions in each version include weighted-average threshold indicators based on all the underlying share classes, the weighted-average running variable, and the full set of controls. ${ }^{31}$ For comparability, we begin with a version where the unit of observation is the mutual fund (i.e., an alternative version of Table 5). Next, we aggregate across portfolios so that all funds with the same management team in the same broad category become a single observation. ${ }^{32}$ In the third version, all funds with the same primary manager in the same (broad) category become a single observation. Because Morningstar does not appear to list managers in alphabetical order, we assume that the primary manager is the manager listed first by Morningstar. ${ }^{33}$ In the last version, we aggregate across all funds within the family that are in the narrow Morningstar category, which allows us to test for diseconomies of scale at the family level for each asset class.

Looking across the four tables, we see that the flow effects that tend to be both larger and

\footnotetext{
${ }^{31}$ Regressions in Tables A4 and A5 include narrow Morningstar category-by-time fixed effects. Regressions in Tables A6 and A7, which aggregate portfolios to the level of the broad Morningstar category, switch to broad Morningstar category-by-time fixed effects.

${ }^{32}$ Broad categories are the categories used in Table 5: Large-cap equity, Mid-cap equity, Small-cap equity, Sector funds, International equity, Taxable bonds, and Municipal bonds.

${ }^{33}$ For funds with two named managers, manager names are listed in alphabetical order only $52 \%$ of the time.
} 
more highly significant than in Table 5. However, because the sixteen return effects that we report for each type of fund almost always contain a mixture of signs and magnitudes, few other patterns emerge. At both the fund-level (Table A4) and the family-category level (Table A7), we continue to find positive return effects for mid-cap equity. At the management team and primary-manager-levels, we find negative return effects for municipal bonds in months $t+18$ and $t+24$, but the magnitudes are quite small. Five of the sixteen estimated return effects for large capequity are negative and statistically significant (at the 10-percent level and below), but the implied diseconomies of scale are the same as in Table 5 (because the flow effects and return effects are both larger). Finally, five of the sixteen estimated return effects for sector funds are negative and statistically significant, while another is positive and statistically significant. To the extent that we find evidence of meaningful diseconomies of scale in this section, it is only with respect to sector funds, and only in the fund-level regressions.

\section{E. A Comparison of Wald and OLS Estimates of Diseconomies of Scale}

Our regression discontinuity approach allows us to directly estimate the causal impact of rating thresholds on flows and the causal impact of rating thresholds on returns. However, we are ultimately interested in measuring the causal impact of flows on returns. To obtain a Wald estimate of the diseconomy of scales for a particular subsample of mutual funds and investment horizon, we scale the estimated coefficient from the reduced-form by the estimated coefficient from the first stage. For example, for the "All equity" sample of funds through month $t+24$, one percentage point in incremental flows is associated with incremental returns that are 0.03 percentage points lower. (The Wald estimate of -0.03 equals -0.07 divided by 2.29 .)

Table 6 reports Wald estimates for different sets of mutual funds and investment horizons alongside the first-stage and reduced-form estimates (from Table 5). Eleven of the 28 Wald esti- 
mates are negative. ${ }^{34}$ Among the seven mutually exclusive categories of funds, nine of the 19 Wald estimates are negative. However, the standard errors associated with many of the estimates are quite large, particularly at longer time horizons and in categories with smaller inflow effects.

In the last several columns of Table 6, we compare our Wald estimates to the partial correlation between fund size and fund returns that we estimate within the same sample using standard OLS regressions (i.e., using a specification similar to that used in $\mathrm{CHHK}$ and numerous other papers). Specifically, the partial correlation for each asset class and investment horizon is estimated as the coefficient on fund size in a regression of future returns on the variables listed under fund characteristics in Table 1, a control for past-12-month log returns, and a separate fixed effect for each Morningstar category each month. Consistent with the existence of diseconomies of scale, each of the negative Wald estimates is significantly more negative than the corresponding OLS estimate. However, the average Wald estimate is 0.028 versus an average OLS estimate of -0.002 . Similarly, the median Wald estimate is 0.007 versus a median OLS estimate of -0.002 . Because of the larger standard errors on the Wald estimates, we can only reject the hypothesis that the OLS and Wald estimates are equal in the six cases where the Wald estimate is statistically significant from zero (the $p$-values of the Hausman tests range from 0.02 to 0.09 ). Furthermore, in all six of these cases, which apply to mid-cap equity and municipal bond funds, the Wald estimate is actually more positive than the OLS estimate, suggesting the existence of (small) economies of scale.

\section{F. Robustness: Estimating Diseconomies of Scale From Changes in Morningstar Ratings}

To test for diseconomies of scale, we have been comparing the future flows and future returns of funds whose current returns are near thresholds for specific Morningstar ratings. This approach is

\footnotetext{
34 The fact that the estimated flow effects in Table 5 are negative for small-cap equity funds for months $\mathrm{t}+12, \mathrm{t}+18$, and $t+24$ prompts us to drop these subsample-horizon combinations from Tables 6 and 7 .
} 
inherently cross-sectional. The rating thresholds that we use in month $t$ are those that Morningstar uses to determine its rating in month $t$. In this section, we take a different approach and use time-series changes in fund ratings to test for diseconomies of scale. When we modify our baseline flow regression to include both the Morningstar star rating in month $t-1$ and the change in Morningstar star ratings between month $t$ and $t-1$, the (unreported) estimated coefficient on the change in ratings variable is $4.6 \%$ (standard error of $0.2 \%$ ). This suggests that gaining one star is associated with a $4.6 \%$ increase in fund size over the next 12 months. While $4.6 \%$ is two times the full-sample estimate of $2.3 \%$ in Table 4 , time-series changes in fund ratings are less plausibly exogenous than the cross-sectional differences in fund ratings that we exploit above.

To identify exogenous changes in Morningstar ratings, we exploit a significant change in how Morningstar ratings are determined. Through May 2002, fund ratings are based on rankings "across four broad asset classes (U.S. stock, international stock, taxable bond, and municipal bond)." However, beginning in June 2002, funds are "ranked and rated within nearly 50 Morningstar Categories." 35 This change in methodology increases the ratings of the top performing funds in investment categories with lower average returns, and decreases the ratings of the nottop-performing funds in investment categories with higher average returns. The standard deviation of the variable measuring changes in ratings jumps from 0.3 stars within the full sample to 0.9 stars in June 2002. When we limit the flow regression sample to June 2002, the estimated coefficient on the change in ratings variable is again $4.6 \%$ (standard error of 1.0\%).

The advantage of focusing on June 2002 is that, if we treat the changes in ratings in this month as being purely exogenous, they provide another strong first stage. The disadvantage is that we are limited to a single (noisy) cross-section of mutual fund returns. In the reduced-form

\footnotetext{
35 See the Morningstar Press Release titled "Morningstar, Inc. to Change "Star Rating" for Funds", dated April 22, 2002 .
} 
regression, the coefficient on the change in ratings variable is 0.19 percentage points (standard error of 0.16). Combining the first-stage and reduced-form estimates, a one-percentage point increase in fund size is associated with a 0.04 percentage point increase in fund returns (standard error of 0.03 ). This effect is statistically and economically indistinguishable from the 0.01 percentage point increase that we find for "All funds" in Table 6. Therefore, regardless of whether we focus on our preferred regression discontinuity estimates or estimates based on changes in the Morningstar rating system, we find little evidence that fund size erodes performance.

\section{G. How are Incremental Flows Invested?}

There are two reasons why incremental flows might not depress fund returns. First, incremental flows may be closet indexed rather than actively managed. This is what the Berk-Green model assumes will happen when a fund's assets under management exceed the optimal level for its manager. Second, incremental flows may be used to deepen existing positions, but without generating enough price impact to significantly harm returns. For example, for sector funds in month $t+12$, flows rise 8.54 percentage points and after-fee returns fall 0.11 percentage points. The Wald estimate is that a 1 percentage point increase in size is associated with a 2 basis point decrease in returns (standard error is 6 basis points). This decrease is consistent with incremental flows being invested at prices that are approximately $2 \%$ too high, which may be plausible given that sector funds are constrained to a limited number of stocks.

In Table 7, we examine how incremental flows are invested. We begin by estimating a reduced-form regression with the number of equity holdings as the dependent variable. This specification measures the casual impact of incremental flows associated with the 4/5-star and 3/4-star boundaries on the number of equity holdings. The sample is limited to non-specialty domestic equity funds for which we observe quarterly holdings. We do not find any evidence 
that the number of holdings increases in response to incremental flows. Instead, our findings suggest that incremental flows are used to deepen existing positions, which is what Pollet and Wilson (2008) find when they treat net flows as exogenous. ${ }^{36}$

Next, we sort the sample of domestic equity funds into two groups based on the number of stocks they hold. Our hypothesis is that funds with fewer stocks than the median fund (within the same investment objective in the same month) may be more likely to actively manage their incremental flows. If so, funds with more concentrated portfolios may be the most likely to exhibit diseconomies of scale. Although the standard errors are higher than in our main tables, we find some evidence that incremental flows are higher in funds with more concentrated portfolios. This finding suggests that investors prefer to invest in more actively managed funds. However, we find no evidence that funds with more concentrated portfolios earn lower returns than funds with less concentrated portfolios.

\section{H. Robustness: Variation in Fund and Family Characteristics}

In a final set of robustness tests, we re-estimate flow and return regressions for different partitions of the "All funds," "All equity," and "All bonds" samples. We report these results in Appendix Tables A8, A8A, and A8B, respectively. We find stronger flow effects into smaller funds (i.e., those of below median size within their category) and younger funds (i.e., those between 3 and 5 years old). (The standard errors are too large to conclude anything definitive about the sample of small and young funds.) We also find stronger flow effects into smaller families; funds that we classify as being more actively managed (based on their correlation with the best-fit index as reported by Morningstar); and load funds. While these patterns suggest that investors place more weight on Morningstar ratings when investing in funds for which recent

\footnotetext{
${ }^{36}$ In unreported regressions, we test for changes in the Cremers-Petajisto (2009) active share measure. The estimated coefficients are positive, suggesting that incremental flows are driving portfolio weights further from benchmark weights, but the standard errors are large.
} 
returns may be relatively more informative about manager skill — or when they are investing through a broker - the return effects remain both economically small and statistically indistinguishable from zero. Of the 44 estimates from return regressions based on differences in fund and family characteristics in the "All funds" sample, only 12 are negative. The final comparison divides the sample into periods before and after November 2000, when Regulation Fair Disclosure (Reg FD) went into effect. We find slightly stronger flow effects, but similar return effects, in the post-Reg FD period.

\section{Summary}

While our identification strategy necessarily limits the variation in fund size that can be used to test for scale diseconomies, it is important to note that we are testing for scale diseconomies at many different points in the size distribution. We separately examine asset classes where Morningstar rating effects are large (e.g., sector funds and international equity) or modest but precisely estimated (large-cap equity, municipal bonds). We also separately examine asset classes where diseconomies of scale are most likely because managers have limited securities to chose from (sector funds), where there is more room to invest additional assets (large-cap equity), and where economies of scale may be most likely, due to large trades having lower trading costs (bonds). The change in rating system in 2002 gives us a completely different, but still plausibly exogenous, source of identification, as well as a few examples of rating changes of more than one star. None of these estimates support the view that diseconomies of scale meaningfully erode performance. Finally, while the Berk-Green model assumes that incremental flows by domestic equity funds will be indexed, we find that they are used to deepen existing positions. Financial markets appear liquid enough that even the latter practice does not have a significant impact on returns. 


\section{Adjusting Performance Persistence for Diseconomies of Scale}

Finally, we turn to the important question of whether our estimated diseconomies of scale have an economically significant impact on estimates of performance persistence. Berk and Green (2004) show that the combination of diseconomies of scale with endogenous fund flows will cause researchers to underestimate the true degree of performance persistence in the mutual fund industry. In Table 8, we adjust measures of performance persistence for the causal impact of flows on performance. To begin, we estimate standard OLS regressions that predict future returns from past 12-month returns, as well as the category-by-month fixed effects and the control variables included in Tables 2-7. We report the estimated coefficient on the past return measure, and its standard error, in the first set of columns. Within the full sample of funds, assuming a 12month horizon, the estimated coefficient is 0.091 . However, this estimate will be downwardly biased if past returns attract incremental flows and there are diseconomies of scale.

We use a similar set of regressions to predict the impact of past returns on log net flows. We report the estimated coefficient on the past return measure, and its standard error, in the second set of columns. For the full sample of funds, an additional percentage points in returns over the past 12 months is associated with 0.947 percentage points in additional flow. The larger the diseconomies of scale associated with these additional flows, the greater the downward bias in the persistence coefficient.

Finally, we use the diseconomies of scale that we estimated in the prior section to adjust the persistence coefficient. Specifically, we estimate the "Corrected persistence coefficient" as the "Persistence coefficient" minus the "Flow coefficient" times the "Causal effect of flows" from Table $6 .^{37}$ For the full sample of funds and a 12-month horizon, adjusting for diseconomies

\footnotetext{
${ }^{37}$ The "Persistence coefficient" is the increase in expected next-period percentage point return associated with a one percentage point increase in 12-month past returns. The "Flow coefficient" times the "Causal effect of flows" is the
} 
of scale decreases the persistence correlation from 0.091 to 0.078 . If we use the standard errors from Table 6 to construct a 95\% confidence interval for the corrected persistence coefficient, we find that it ranges from 0.015 to 0.142 . We cannot reject the hypothesis that the "Persistence coefficient" and "Corrected persistence coefficient" are equal. However, we can reject at the 1percent level the hypothesis that the corrected persistence coefficient is equal to 0.42 , which is the value implied by Berk and Green's calibration. ${ }^{38}$ On the other hand, we also can reject the hypothesis that the corrected persistent coefficient is zero.

Within investment categories, the corrected persistence coefficient is less precisely estimated. As we possess data on virtually every U.S. mutual fund in operation between December 1996 and August 2009, it may prove difficult to significantly increase the statistical power of our tests. Nevertheless, the upper bound of the $95 \%$ confidence interval of the corrected persistence coefficient is typical no more than twice the OLS estimate, and it tends to be lower in categories where we expect diseconomies of scale to be largest. For sector funds the corrected persistence coefficient is slightly higher than the unadjusted persistence coefficient ( 0.080 versus 0.069$)$, but the upper bound of the $95 \%$ confidence interval is only 0.168 . In contrast, we obtain the largest upper bound (0.433) for "Large-cap Equity", a category for which we expect diseconomies of scale to be relatively small. Our inference, based on our empirical strategy for identifying exogenous variation in fund size, is that correcting for scale diseconomies does not significantly affect our view of performance persistence.

expected percentage point decrease in next period's return based on the expected percentage point increase in flows times the expected diseconomies of scale associated with the incremental flow. The "Corrected persistence coefficient" removes the impact of return-induced flows on the expected percentage point increase in next period's return.

${ }^{38}$ In Berk and Green's calibration exercise, managers' skill, defined as the annualized alpha they would achieve in the absence of scale diseconomies, is distributed normally with a mean of $6.5 \%$ and a standard deviation of $6.0 \%$. Given the within-objective standard deviations of returns of $7.4 \%$ over the past 12 months, in the absence of scale diseconomies, this distribution of alpha would imply (within-objective) persistence coefficients of 0.42 . 


\section{Conclusion}

We use a regression discontinuity approach to test for fund-level diseconomies of scale in the mutual fund industry. Specifically, we use the discrete changes in flows associated with discrete changes in Morningstar ratings to identify flows that should only impact fund returns through diseconomies of scale. On the one hand, the confidence intervals around the estimates of scale diseconomies implied by these plausibly exogenous flows are wider than those implied by crosssectional comparisons of large and small funds. This raises the possibility that diseconomies of scale are larger than previously estimated, perhaps because more-skilled managers do, in fact, manage larger funds. On the other hand, when we use our diseconomies of scale estimates to adjust standard measures of performance persistence, the upper bounds of the confidence intervals are still too low to significantly change our views about the extent of performance persistence in the U.S. mutual fund industry. In practical terms, we conclude that any downward bias in OLS estimates of diseconomies of scale and performance persistence in prior and future studies of manager skill is likely to be small. 


\section{REFERENCES}

Amihud, Yakov and Ruslan Goyenko. 2013. "Mutual Fund's R ${ }^{2}$ as Predictor of Performance." Review of Financial Studies 26, 667-694.

Berk, Jonathan, and Richard Green, 2004, "Mutual Fund Flows and Performance in Rational Markets," Journal of Political Economy 112, 1269-1295.

Berk, Jonathan, 2005, "Five Myths of Active Portfolio Management," UC-Berkeley mimeo. http://faculty.haas.berkeley.edu/berk/papers/myth.pdf.

Berk, Jonathan, and Jules van Binsbergen, 2012, "Measuring Managerial Skill in the Mutual Fund Industry" NBER Working Paper \#1814.

Blake, Christopher and Matthew Morey, 2003, "Morningstar Ratings and Mutual Fund Performance," Journal of Financial and Quantitative Analysis 35, 451-483.

Blume, Marshall, 1998, "An Anatomy of Morningstar Ratings," Financial Analysts Journal 54, 19-27.

Card, David, 1999, "The Causal Effect of Education on Earnings," Handbook of Labor Economics, Vol 3, Part 1, ed. Orley Ashenfelter and David Card, North Holland.

Carhart, Mark, 1997, "On Persistence in Mutual Fund Performance," Journal of Finance 52, 57 82.

Chevalier, Judith, and Glenn Ellison, 1997, "Risk Taking by Mutual Funds as a Response to Incentives," Journal of Political Economy 105, 1167-1200.

Chen, Joseph, Harrison Hong, Ming Huang, and Jeffrey Kubik, 2004, "Does Fund Size Erode Mutual Fund Performance? The Role of Liquidity and Organization," American Economic Review 94, 1276-1302.

Chen, Joseph, Harrison Hong, Wenxi Jiang, and Jeffrey Kubik, 2013, "Outsourcing Mutual Fund Management: Firm Boundaries, Incentives and Performance," Journal of Finance 68, 523558.

Cici, Gjergi, Scott Gibson, John Merrick, 2011, "Missing the Marks? Dispersion in Corporate Bond Valuations Across Mutual Funds," Journal of Financial Economics 101, 206-226.

Cremers, Martijn and Antti Petajisto, 2009, "How Active is Your Fund Manager: A New Measure That Predicts Performance," Review of Financial Studies 22, 3329-3365.

Del Guercio, Diane, and Paula Tkac, 2008, "Star Power: The Effect of Morningstar Ratings on Mutual Fund Flow," Journal of Financial and Quantitative Analysis 43, 907-936.

Doll, Richard, 1998, "Uncovering the Effects of Smoking: Historical Perspective," Statistical Methods in Medical Research 7, 87-117.

Edelen, Roger, 1999, "Investor Flows and the Assessed Performance of Open-end Fund Managers," Journal of Financial Economics 53, 439-466.

Edelen, Roger, Richard Evans, and Gregory Kadlec, 2007, "Scale Effects in Mutual Fund Performance: The Role of Trading Costs," Working Paper.

Elton, Edwin, Martin Gruber, and Christopher Blake, 2012, "Does Mutual Fund Size Matter? The Relationship Between Size and Performance," Review of Asset Pricing Studies 2, 31-55.

Evans, Richard, 2010, "Mutual Fund Incubation," Journal of Finance 65, 1581-1611.

Farnsworth, Heber, 2013, "Performance Evaluation, Contracts, and Flows in Efficient Markets," Working Paper.

Glode, Vincent, 2011, “Why Mutual Funds 'Underperform'," Journal of Financial Economics $99,546-559$.

Gutierrez, Ro, William Maxwell, and Danielle Xu, 2009, “On Diseconomies of Scale and Persis- 
tent Performance in Corporate-Bond Mutual Funds," Working Paper.

Iliev, Peter, 2010, "The Effect of SOX Section 404: Costs, Earnings Quality, and Stock Prices," Journal of Finance 65, 1163-1196.

Imbens, Guido, and Thomas Lemieux, 2008, "Regression Discontinuity Designs: A Guide to Practice," Journal of Econometrics 142, 615-635.

Jensen, Michael, 1968, "The Performance of Mutual Funds in the Period 1945-1964," Journal of Finance 23, 389-416.

Kacperczyk, Marcin, Clemens Sialm, and Lu Zheng, 2005, "On the Industry Concentration of Actively Managed Equity Mutual Funds,” Journal of Finance 60, 1983-2012.

Kacperczyk, Marcin, Clemens Sialm, and Lu Zheng, 2008, "Unobserved Actions of Mutual Funds," Review of Financial Studies 21, 2379-2416.

Lee, David, and Thomas Lemieux, 2009, "Regression Discontinuity Designs in Economics," NBER Working Paper \#14723.

Lou, Dong, 2012, "A Flow-Based Explanation for Return Predictability," Review of Financial Studies 25, 3457-3489.

Massimo, Massa, Jonathan Reuter, and Eric Zitzewitz, 2010, "When Should Firms Share Credit with Employees? Evidence from Anonymously Managed Mutual Funds, "Journal of Financial Economics 95, 400-424.

Pastor, Lubos, and Robert Stambaugh, 2012, "On the Size of the Active Management Industry," Journal of Political Economy 120, 740-781.

Pastor, Lubos, Robert Stambaugh, and Lucian Taylor, 2014, "Scale and Skill in Active Management," NBER Working Paper \#19891.

Peter, Laurence and Raymond Hull, 1969, The Peter Principle: Why Things Always Go Wrong, New York: William Morrow and Company.

Pollet, Joshua, and Mungo Wilson, 2008, "How Does Size Affect Mutual Fund Behavior?" Journal of Finance 63, 2941-2969.

Petersen, Mitchell, 2009, "Estimating Standard Errors in Finance Panel Data Sets: Comparing Approaches," Review of Financial Studies 22, 435-480.

Reuter, Jonathan, and Eric Zitzewitz, 2006, "Do Ads Influence Editors? Advertising and Bias in the Financial Media," Quarterly Journal of Economics 121, 197-227.

Sirri, Erik, and Peter Tufano, 1998, "Costly Search and Mutual Fund Flows," Journal of Finance $53,1589-1622$.

Yan, Xuemin, 2008, "Liquidity, Investment Style, and the Relation between Fund Size and Fund Performance," Journal of Financial and Quantitative Analysis 43, 741-768. 


\section{Appendix}

This appendix has three subsections. First, we present tests for manipulation of the forcing variable, the within-category percentile ranking. Second, we examine the robustness of our results to alternative bandwidths around the rating thresholds. Third, we present the additional flow and return regressions that are referenced in Sections IV.D and IV.H.

\section{A.1. Tests for manipulation}

A common concern in regression discontinuity design studies is that agents may be able to manipulate the forcing variable. In our context, the concern would be that funds with more skilled managers might be better at managing their returns (e.g., by time varying the riskiness of their portfolios) in order to maximize their chances of placing just above a Morningstar boundary. If manager skill is correlated with the probability of such manipulation succeeding, this could create a discontinuity in skill at the boundary, confounding our use of the boundary to identify scale diseconomies.

Our prior is that this type of manipulation would be very difficult to do successfully for several reasons. First, the cutoffs for additional stars are not fixed, but depend on the performance of the other funds in a Morningstar category. The median fund*month is in a category with 131 other funds, and so tracking and forecasting the performance of the others funds that are close to a cutoff would be non-trivial. Second, attempting to manage returns through the variation of risk (e.g., as in Chevalier and Ellison, 1997) would be difficult for most mutual funds, which often are restricted in their use of leverage or short selling. Manipulating returns through discretion in the valuation of less-illiquid assets like corporate or municipal bonds might be more feasible (e.g., Cici, Gibson, and Merrick, 2011), and so we run separate manipulation tests for these asset categories. Third, the Morningstar ranking methodology is complicated. We are 
therefore more concerned about manipulation before June 2002, when the methodology became substantially more complicated, and conduct separate tests for the pre-2002 period.

Given these concerns, we are therefore not that surprised that our tests fail to find evidence of successful manipulation, even in the time periods and asset classes where our concerns are the greatest. We conduct three types of tests: 1) McCrary (2008) tests for discontinuities in the density of the forcing variables at rating cutoffs, 2) tests for discontinuities in the control variables at the rating cutoffs, and 3) fund-level tests for persistence in the discontinuity variable (controlling for the forcing variable). The first two tests are fairly standard in regression discontinuity studies, while the third addresses a form of manipulation that would be particularly problematic for our methodology.

\section{A.1.1. McCrary tests for discontinuities}

McCrary outlines a simple test for manipulation of the forcing variable. If agents successfully manipulate the forcing variable to just exceed a cutoff, then we should observe a discontinuity in the density of the variable at the cutoff. As successful manipulators would be more common just above the cutoff, to the extent that skill in manipulation was correlated with skill in fund management, this could create a discontinuity in skill at the cutoffs, and thus be a threat to identification.

The McCrary test involves defining a bandwidth, calculating the number of observations in each bin, and testing whether the number of observations in each bin changes discretely at the boundary. Morningstar ratings are defined based on within-category percentile rankings on riskadjusted returns. Because the density of a percentile variable cannot vary, we test for discontinuities in the density of Morningstar's measure of risk-adjusted returns. For simplicity, we test for discontinuities at the boundaries of the 3,5 and 10-year star ratings, without considering whether 
a boundary is pivotal for a fund's overall rating. As in the main analysis, we restrict attention to a fund's largest share class, which for the reasons discussed above is the rating funds are most likely to have an interest in manipulating.

In order to aggregate results over investment categories with different standard deviations of returns, we first standardize returns into z-scores within each objective*month. If returns were normally distributed, the 4 cutoffs would be at z-scores of approximately $-1.28,-0.45,0.45$, and 1.28. In practice, the average and standard deviation $\mathrm{z}$-score boundaries are $-1.13,-0.29,0.46$, and 1.22, reflecting some excess kurtosis and negative skew. The standard deviations are 0.22 , $0.15,0.15$, and 0.24 , reflecting some variation around these averages across objective*months.

After identifying the funds that are just above and below each boundary, we place funds into bins that are 0.01 wide in z-score space and begin just after the first fund on each side of the boundary. Figure A1 plots the share of funds in the 10 bins on either side of the four star bounda-

ries for the 3-year ratings (the time horizon which have the largest sample size). The standard normal density is shown for comparison. There is no evidence of a discontinuity in density, and this is confirmed by statistically insignificant coefficients on a discontinuity variable in a regression with a local linear control. Results are similar for the 5-year and 10-year ratings. They are also similar when we split the sample based on pre/post-2002 and bond/stock funds.

\section{A.1.2. Tests for discontinuities in control and lagged dependent variables}

A second commonly used test for manipulation of the forcing variable is to test whether control and lagged dependent variables exhibit discontinuities. Table A1 replicates the regressions in Table 3 with alternative dependent variables. While most of the control variables covary with the forcing variable, there is no evidence of discontinuities at the rating boundaries. The fact that there are no discontinuities in these pre-determined observable variables increases our confi- 
dence that there is also no discontinuity in manager skill, the key unobservable variable our approach is attempting to control for.

\section{A.1.3. Tests for persistence in the discontinuity variable}

As a final test for successful manipulation of Morningstar ratings, we ask whether certain funds are able to persistently place just above rating thresholds. Morningstar ratings are based on riskadjusted returns over multi-period windows (36, 60, and 120 months), and so the month-tomonth change in a fund's percentile ranking is fairly small (with standard deviations of 6.6, 5.5, and 4.7 percentile points, respectively). As a result, these tests require controlling for the forcing variable non-linearly.

To see this, suppose that if a fund's percentile ranking change is drawn randomly each month from a p.d.f. $f(x)$, with a peak at $x=0$. The probability that a fund will exceed a threshold next month will be given by $\mathrm{F}(\mathrm{z})$, where $\mathrm{z}$ is the current-month distance above the threshold and $\mathrm{F}$ is the c.d.f. Given the peak in $\mathrm{f}()$ at 0 , this probability $\mathrm{F}(\mathrm{z})$ will be non-linear in $\mathrm{z}$ with a slope that peaks at zero. Especially if the spread in $\mathrm{f}()$ is small, controlling for the current-month forcing variable linearly when predicting the future discontinuity could lead one to falsely conclude that there is persistence in the discontinuity variable.

As a result, we use a logit model to predict the future discontinuity variable as a function of the current-month discontinuity and forcing variable, as well as the control variables used in Table 3. Table A2 reports the coefficients on the current-month discontinuity and forcing variable for models predicting the discontinuity variable at the 1, 3, and 6 month horizon. In general, the coefficients on the current-month discontinuity variable are statistically and economically insignificant. In particular, we can usually rule out that being above the boundary this month raises the future probability by more than a 2-percentile increment in the forcing variable. 


\section{A.2. Robustness to bandwidth}

It is common in regression discontinuity studies to check the robustness of the results to alternative choices about the bandwidth analyzed around the discontinuities. The results presented above use a bandwidth of 5 percentiles in either direction of the cutoff for a Morningstar rating. Table A3 replicates selected results from Tables 4 using alternative bandwidths.

The results do not appear sensitive to the choice of bandwidth. Because narrower bandwidths reduce the number of observations included, standard errors rise, particularly if the bandwidth is narrowed to 2 percentiles. Likewise, standard errors decline slightly as the bandwidth widens. The main conclusions are robust to bandwidth: 1) star boundaries are accompanied by discontinuities in flows, 2) discontinuities in flows are larger for the 4/5-star boundary, and 3) discontinuities in flows are rarely accompanied by discontinuities in future returns.

\section{A.3. Additional first-stage and reduced form estimates}

In Section IV.D., we discuss alternative versions of Table 5. In Table A4, we estimate flow and return effects at the fund level, in regressions that include weighted-average threshold indicators based on all the underlying share classes, the weighted-average running variable, and the full set of controls. In Tables A5, A6, and A7, the unit of observation is no longer the mutual fund. We aggregate portfolio to the management-team-by-narrow-Morningstar-category level, primarymanager-by-broad-Morningstar-category level, and family-by-broad-Morningstar-category level, respectively.

In Section IV.H., we discuss regressions where we split the sample of funds into two groups based on different fund and family characteristics, and on the introduction of Regulation Fair Disclosure. The samples being split in Tables A8, A8A, and A8B are "All funds," "All equity," and "All bonds," respectively. 


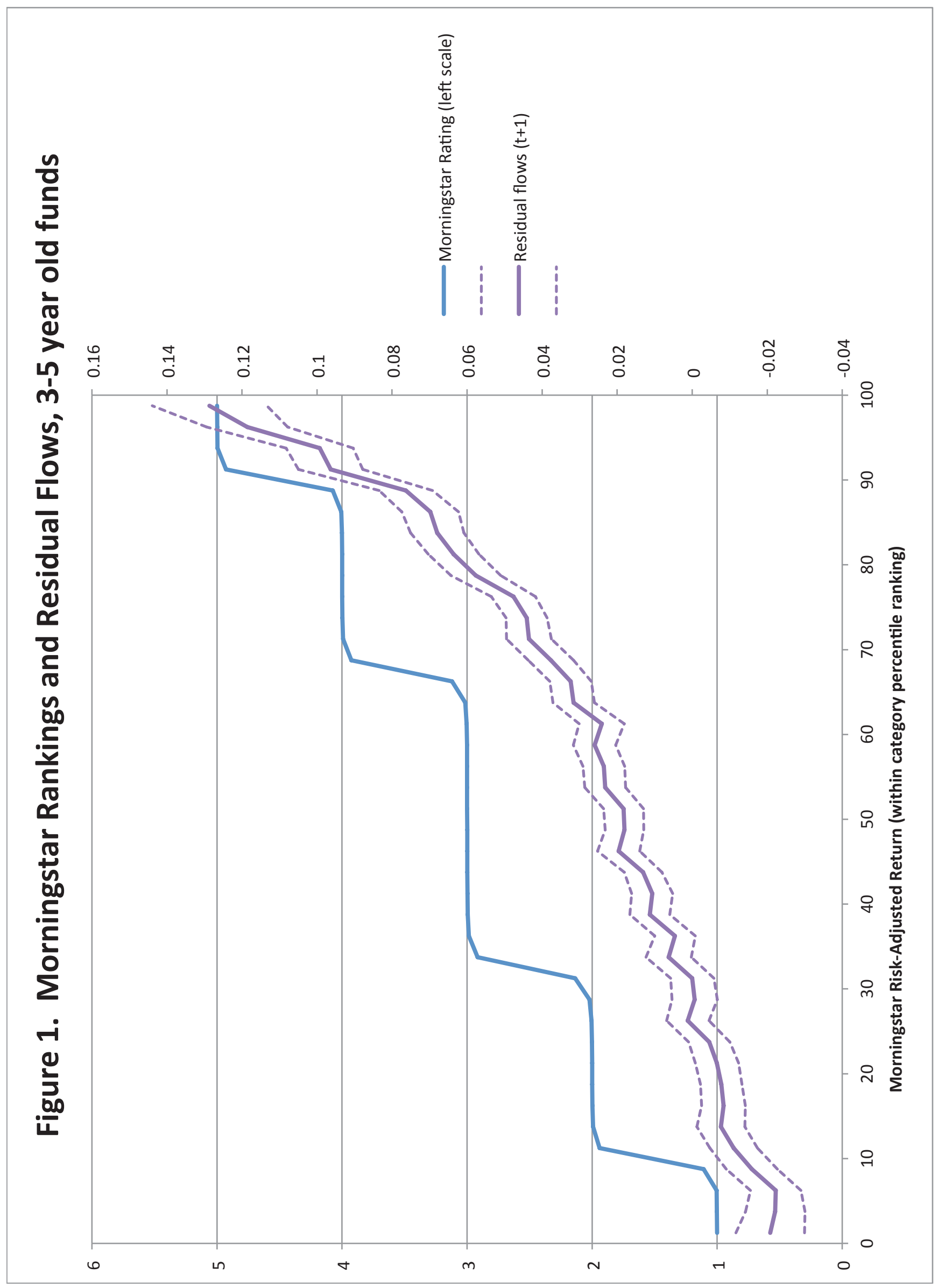




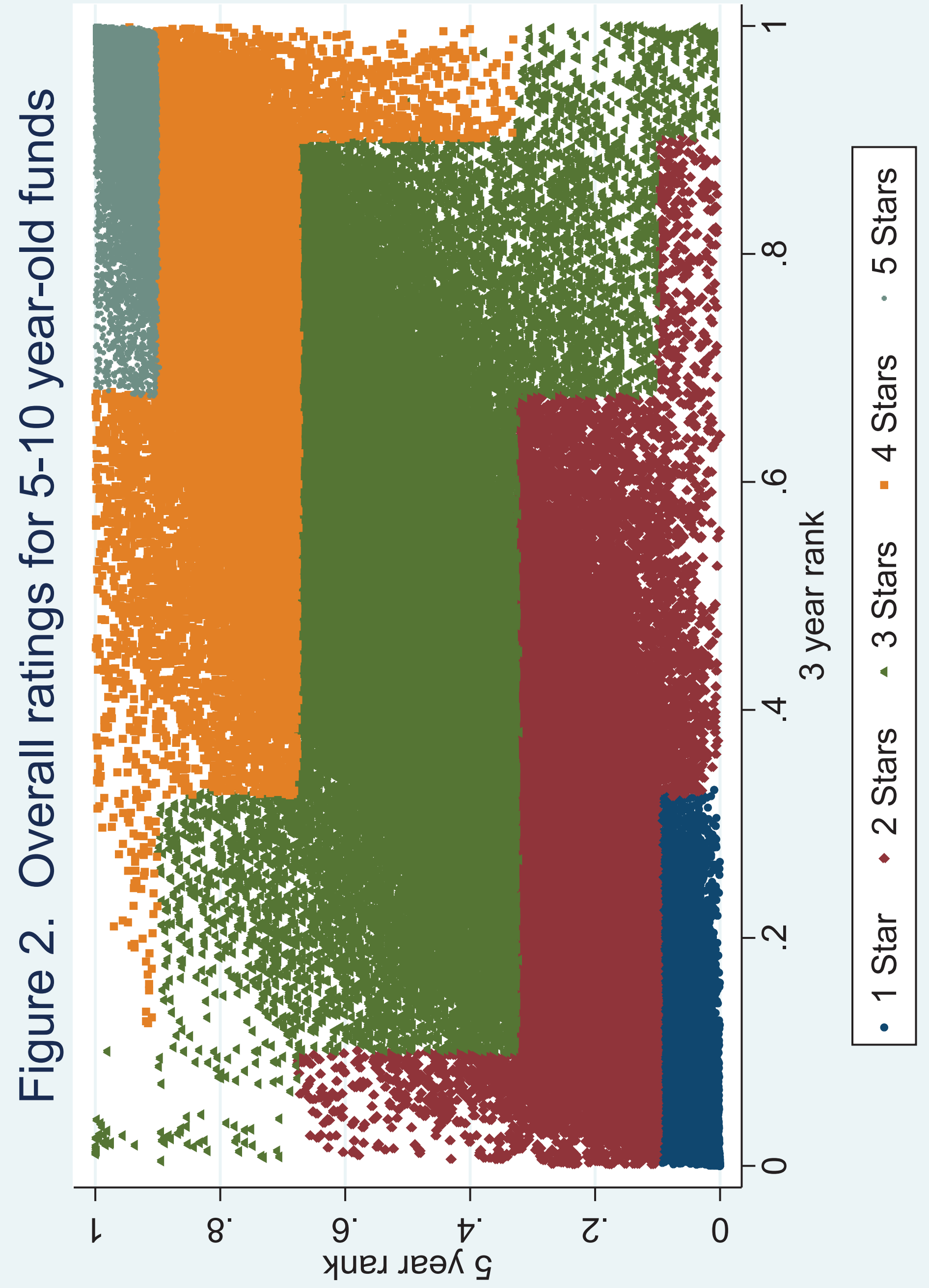




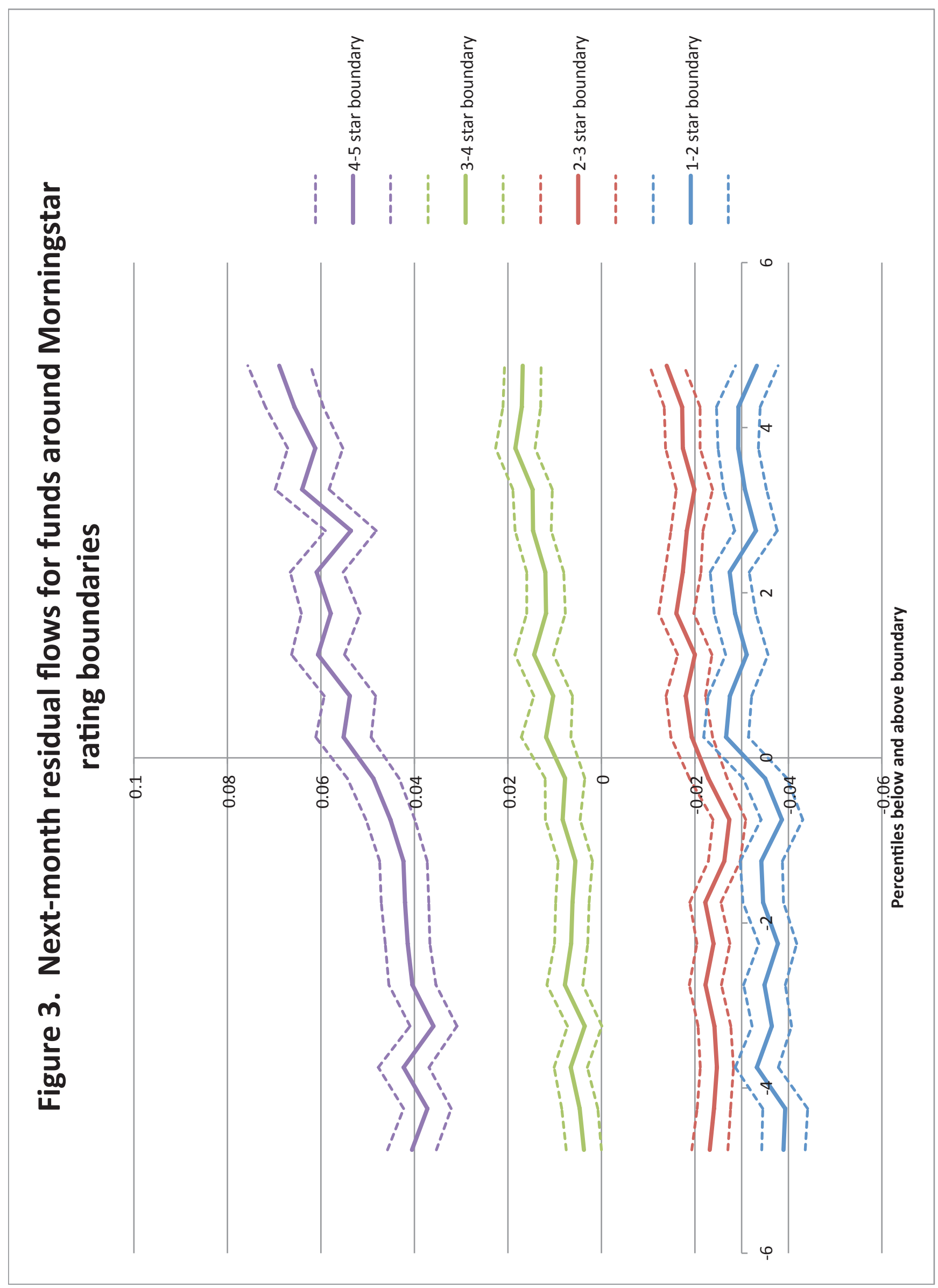




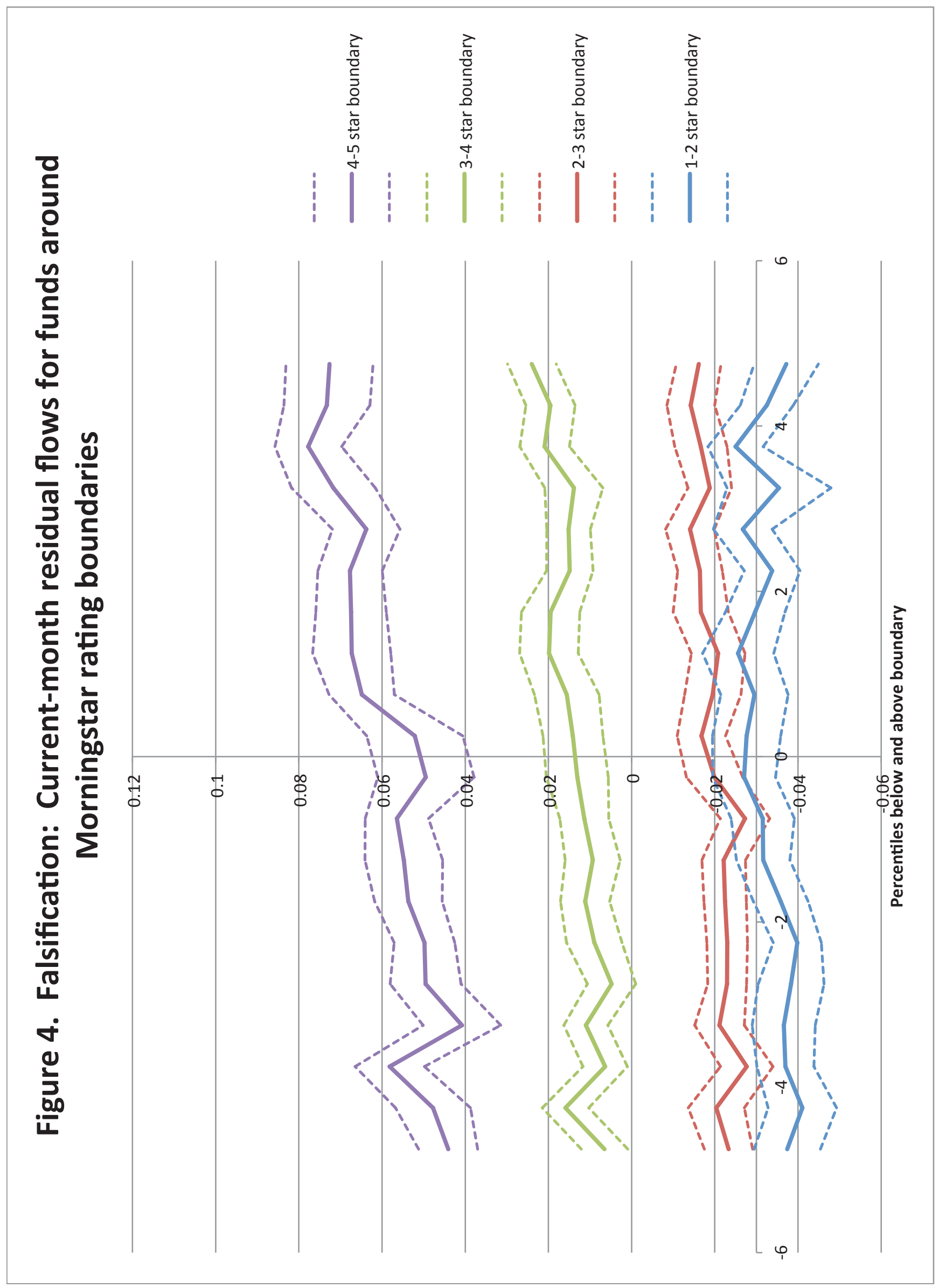




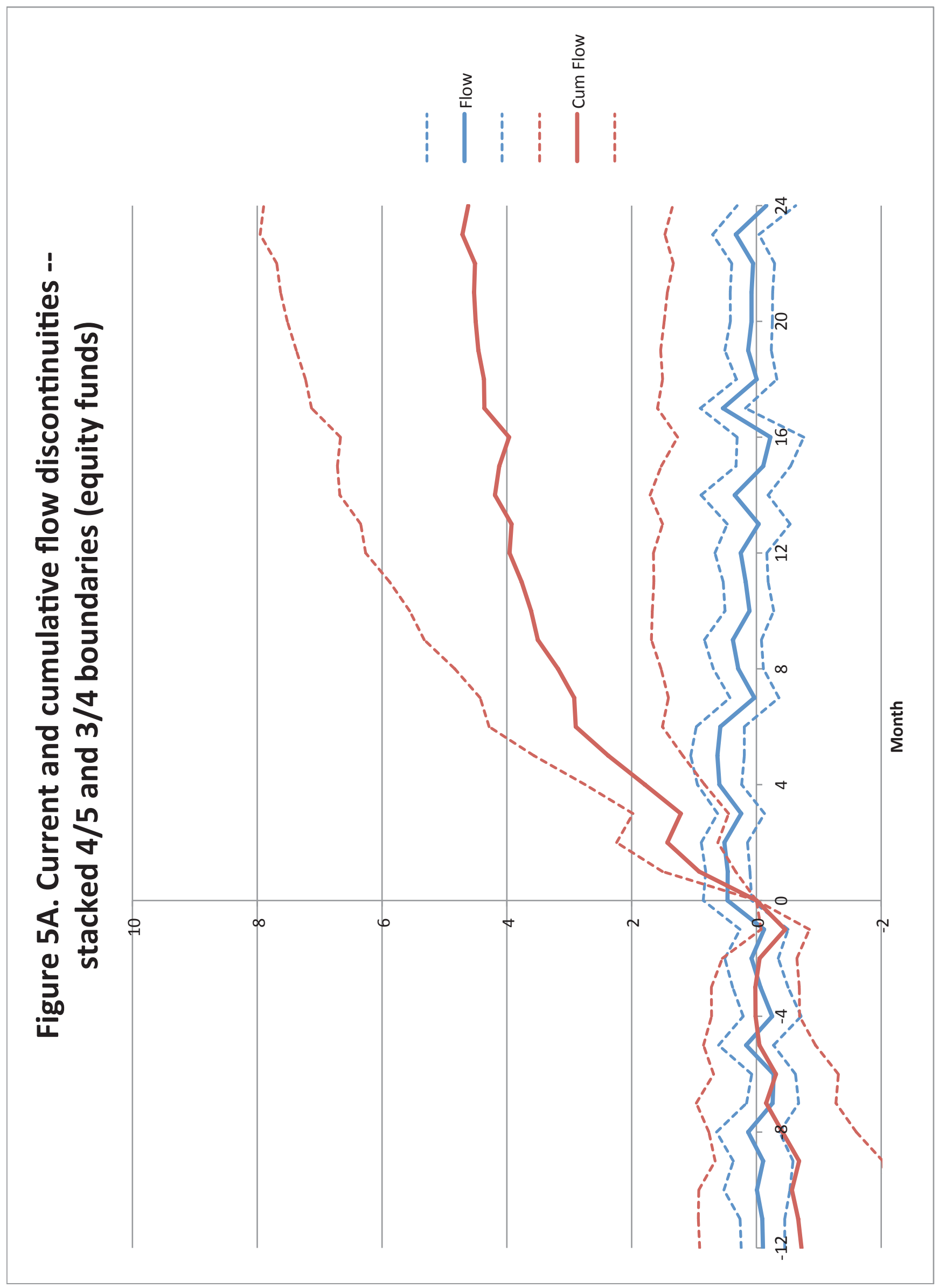




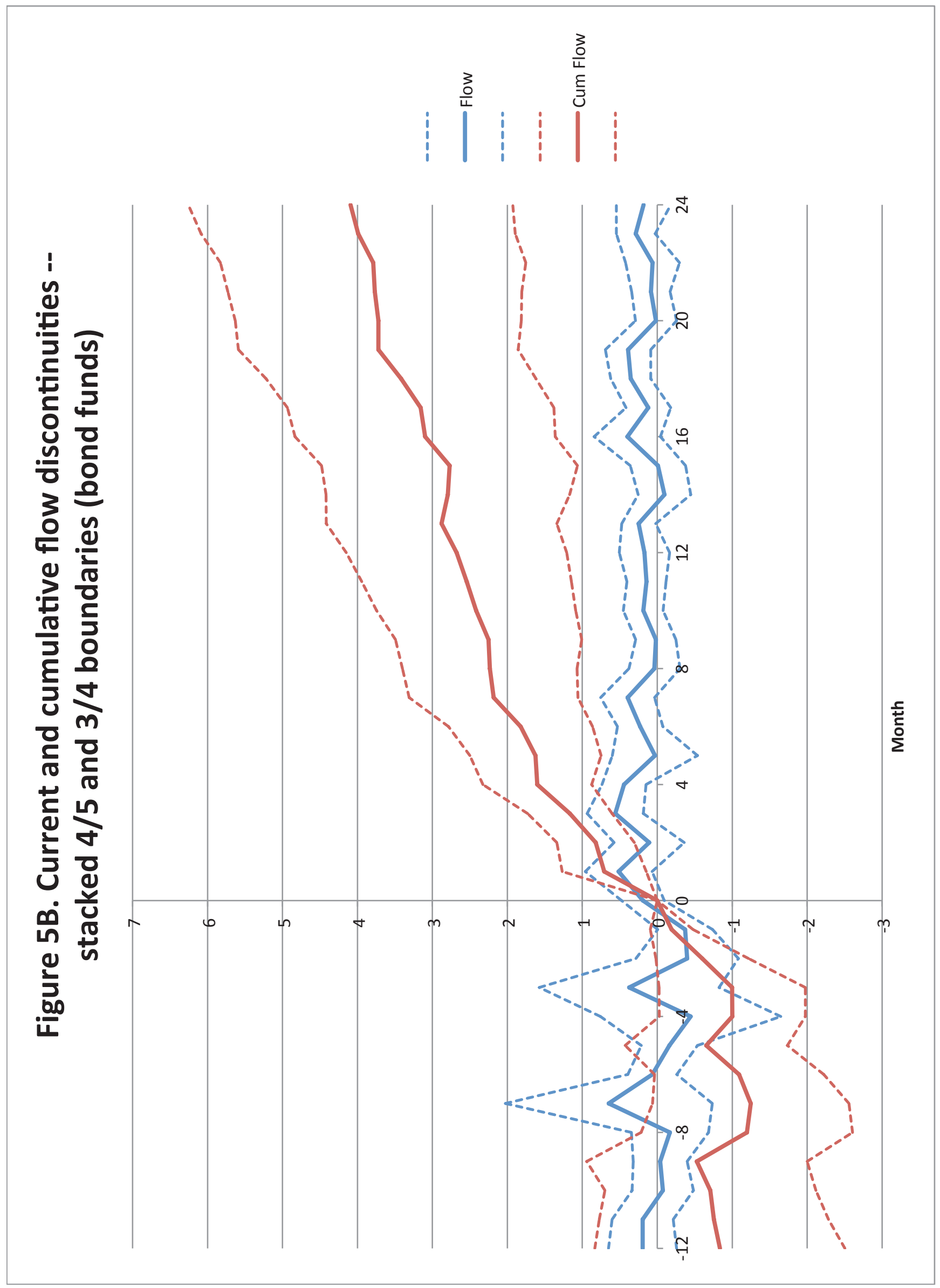




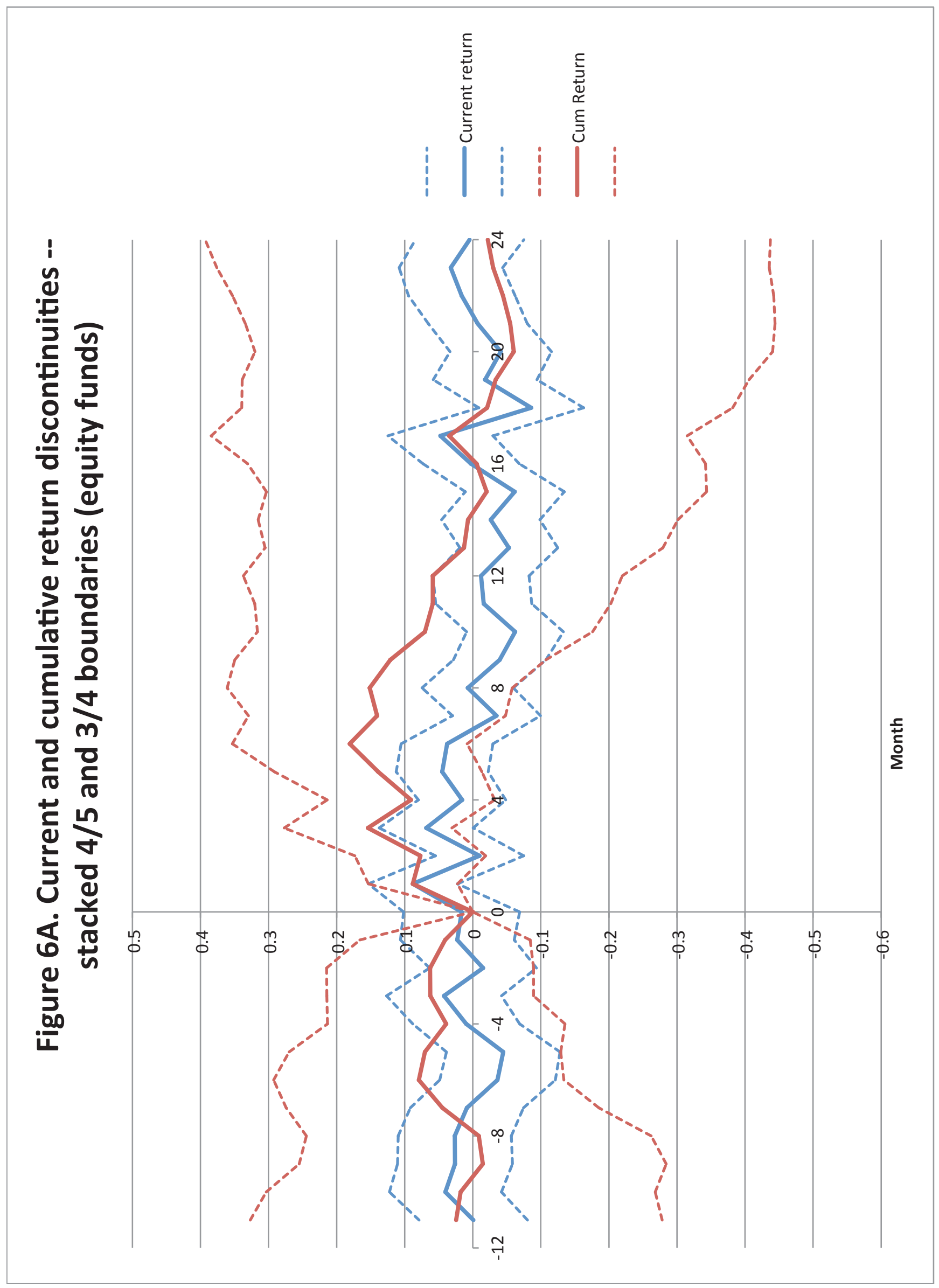




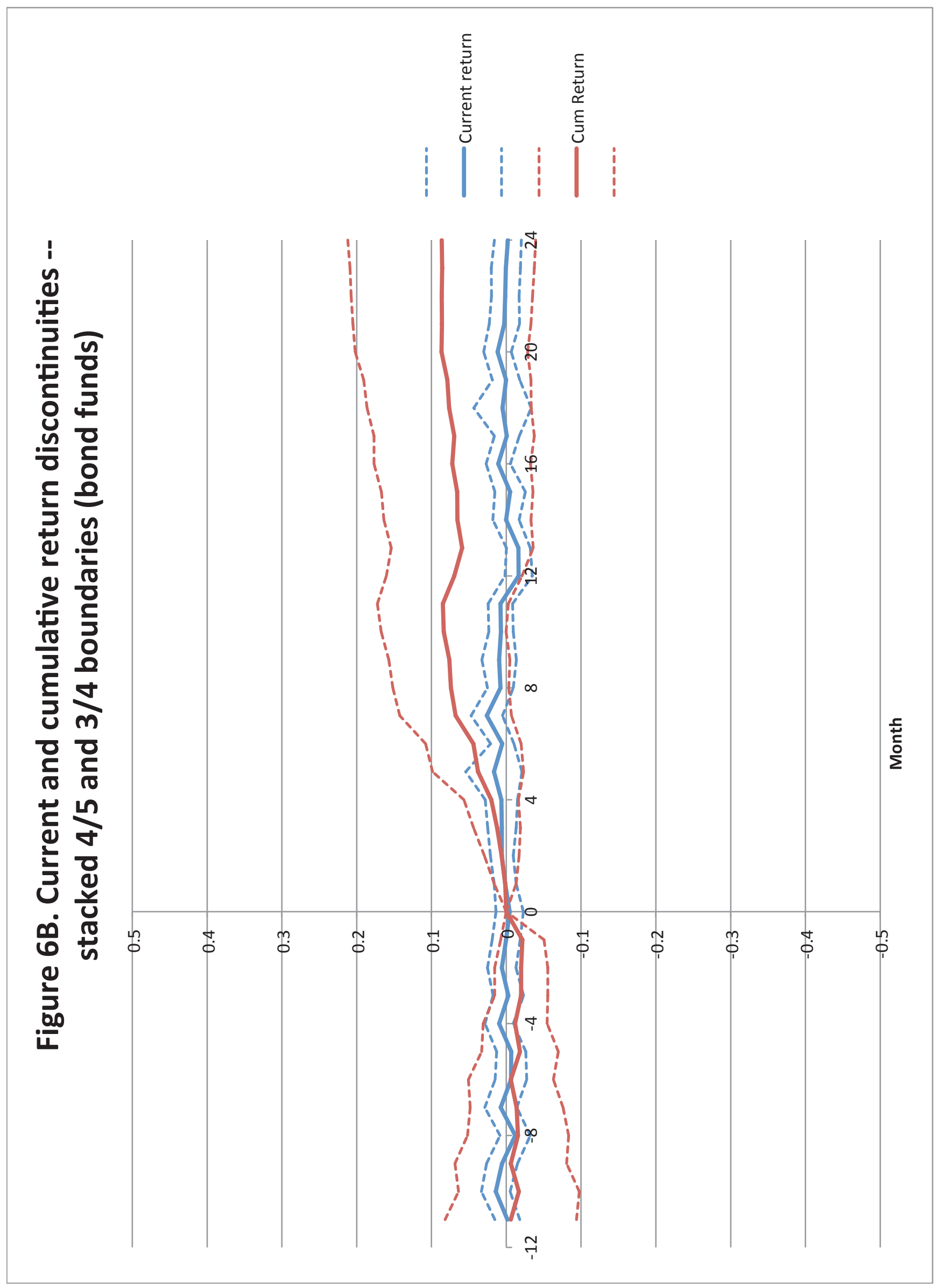


Table 1. Summary statistics

Summary statistics are reported for portfolio*month combinations in which at least one share class receives a Morningstar rating, which requires at least three years of history. Fund characteristics are the average characteristics of the funds' share classes, weighted by prior-month assets. A complete management team change is defined as no overlap in manager surnames with the prior period; any management team change is defined as incomplete overlap in manager surnames. Money market and index funds are excluded.

\begin{tabular}{|c|c|c|c|c|c|c|c|}
\hline & \multicolumn{2}{|c|}{ All funds } & \multicolumn{5}{|c|}{ By (asset-weighted average) Morningstar rating } \\
\hline & Mean & SD & 1 star & 2 stars & 3 stars & 4 stars & 5 stars \\
\hline Number of portfolio*months & \multicolumn{2}{|c|}{475,633} & 34,719 & 98,799 & 171,057 & 120,783 & 50,275 \\
\hline \multicolumn{8}{|c|}{ Returns (cumulative log percentage points, adjusted for category mean) } \\
\hline Percent surviving to $t+24$ months? & 86 & 35 & 73 & 80 & 86 & 91 & 92 \\
\hline Return $(\mathrm{t})$ & 0.0 & 1.8 & -0.6 & -0.2 & 0.0 & 0.2 & 0.3 \\
\hline Return $(t+1)$ & 0.0 & 1.8 & -0.2 & 0.0 & 0.0 & 0.0 & 0.1 \\
\hline Return ( $t+1$ to $t+6)$ & 0.0 & 5.1 & -0.9 & -0.2 & 0.0 & 0.2 & 0.4 \\
\hline Return ( $t+1$ to $t+12)$ & 0.0 & 7.4 & -1.4 & -0.2 & 0.1 & 0.3 & 0.3 \\
\hline Return $(t+1$ to $t+24)$ & 0.0 & 10.0 & -2.1 & -0.2 & 0.1 & 0.4 & 0.4 \\
\hline \multicolumn{8}{|c|}{ Flows (cumulative log percentage points, adjusted for category mean) } \\
\hline Flow $(\mathrm{t})$ & 0.0 & 10.7 & -1.5 & -0.9 & -0.2 & 0.6 & 1.9 \\
\hline Flow $(t+1)$ & 0.0 & 10.5 & -1.4 & -0.9 & -0.2 & 0.6 & 1.9 \\
\hline Flow $(t+1$ to $t+6)$ & 0.0 & 25.7 & -7.2 & -4.7 & -1.1 & 3.3 & 10.0 \\
\hline Flow $(t+1$ to $t+12)$ & 0.0 & 38.3 & -12.0 & -8.1 & -1.9 & 6.0 & 16.4 \\
\hline Flow $(t+1$ to $t+24)$ & 0.0 & 55.7 & -17.8 & -11.7 & -2.8 & 8.9 & 23.2 \\
\hline \multicolumn{8}{|l|}{ Other fund characteristics } \\
\hline Ln(Portfolio TNA) & 5.2 & 1.8 & 4.2 & 4.8 & 5.2 & 5.6 & 5.9 \\
\hline Ln(Family TNA) & 8.9 & 2.3 & 8.0 & 8.8 & 9.0 & 9.2 & 9.2 \\
\hline Expense ratio & 1.20 & 0.71 & 1.74 & 1.37 & 1.15 & 1.03 & 1.03 \\
\hline Expense ratio $(t+12)$ & 1.19 & 0.71 & 1.76 & 1.37 & 1.16 & 1.04 & 1.03 \\
\hline Percent with any load & 69 & 46 & 77 & 78 & 72 & 61 & 54 \\
\hline Portfolio turnover (\%) & 100 & 158 & 150 & 108 & 92 & 88 & 104 \\
\hline Number of share classes & 2.4 & 1.6 & 2.4 & 2.5 & 2.5 & 2.3 & 2.1 \\
\hline Percent of assets in largest share class & 84.3 & 19.6 & 82.6 & 81.7 & 84.0 & 86.1 & 87.3 \\
\hline \multicolumn{8}{|c|}{ Manager characteristics (funds with named managers only) } \\
\hline Complete management team change $(\%)$ & 1.7 & 12.7 & 2.2 & 1.9 & 1.6 & 1.4 & 1.3 \\
\hline Any management team change (\%) & 3.6 & 18.6 & 4.1 & 4.0 & 3.7 & 3.2 & 3.1 \\
\hline Number of managers & 1.77 & 1.05 & 1.72 & 1.80 & 1.80 & 1.76 & 1.72 \\
\hline Number of managers ( $t+6$ months) & 1.79 & 1.06 & 1.71 & 1.81 & 1.81 & 1.78 & 1.75 \\
\hline \multicolumn{8}{|l|}{ Morningstar ratings } \\
\hline Percent with same rating for all share classes & 73 & 44 & 82 & 70 & 70 & 73 & 83 \\
\hline Average rating $(t)$ & 3.10 & 1.07 & 1.03 & 2.01 & 2.99 & 3.97 & 4.97 \\
\hline Average rating ( $t+36$ months) & 3.06 & 1.02 & 2.16 & 2.62 & 2.98 & 3.40 & 3.63 \\
\hline \multicolumn{8}{|l|}{ Average risk-adjusted return percentile score } \\
\hline 3 year & 51 & 29 & 8 & 25 & 48 & 73 & 91 \\
\hline 5 year & 52 & 29 & 5 & 22 & 49 & 76 & 93 \\
\hline 10 year & 51 & 28 & 6 & 23 & 48 & 74 & 91 \\
\hline \multicolumn{8}{|l|}{ Percent of portfolios with: } \\
\hline 5 year rating (5-9 year-old funds) & 83 & 37 & 78 & 84 & 85 & 84 & 77 \\
\hline 10 year rating ( $10+$ year-old funds) & 46 & 50 & 39 & 47 & 48 & 46 & 39 \\
\hline
\end{tabular}



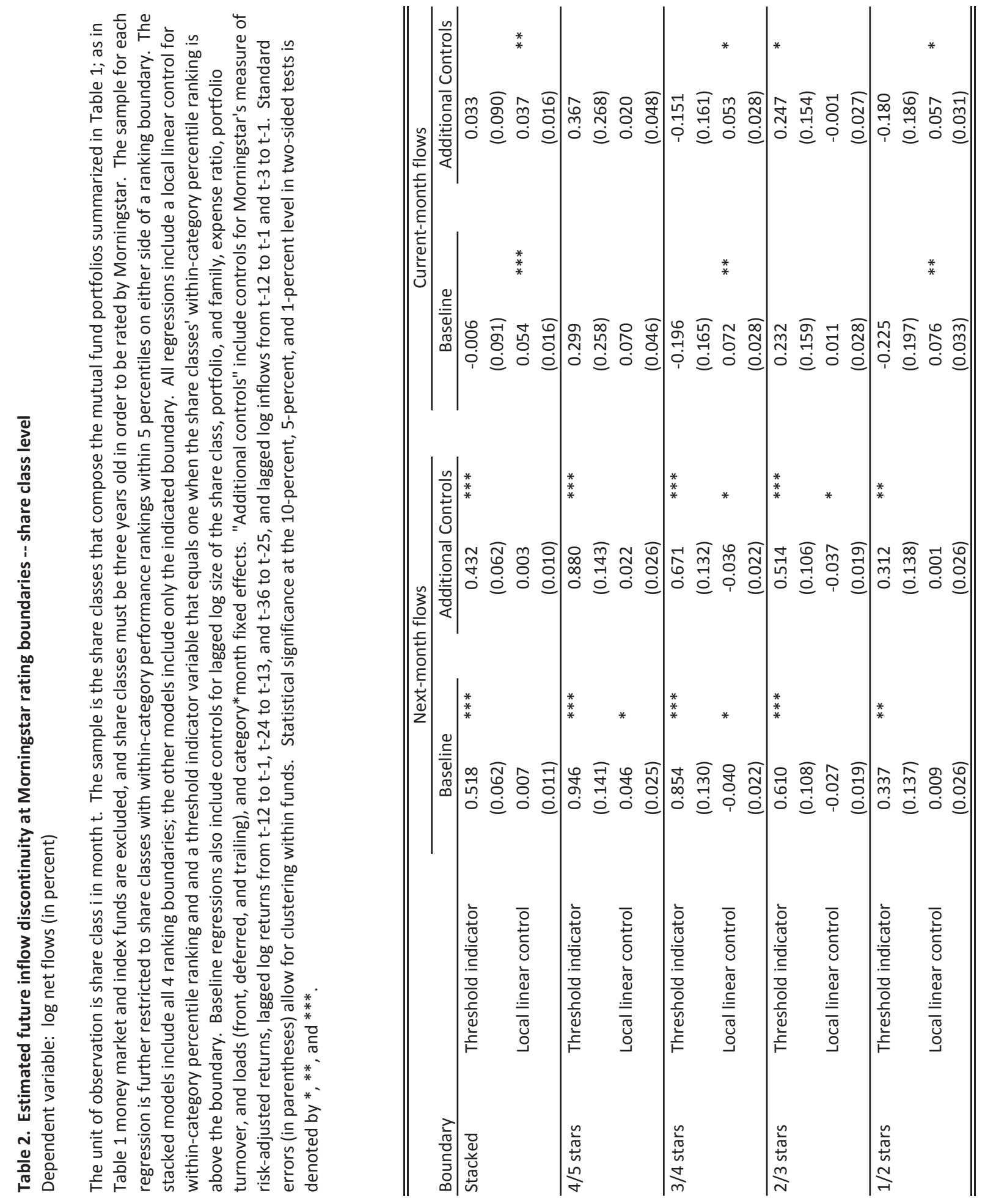

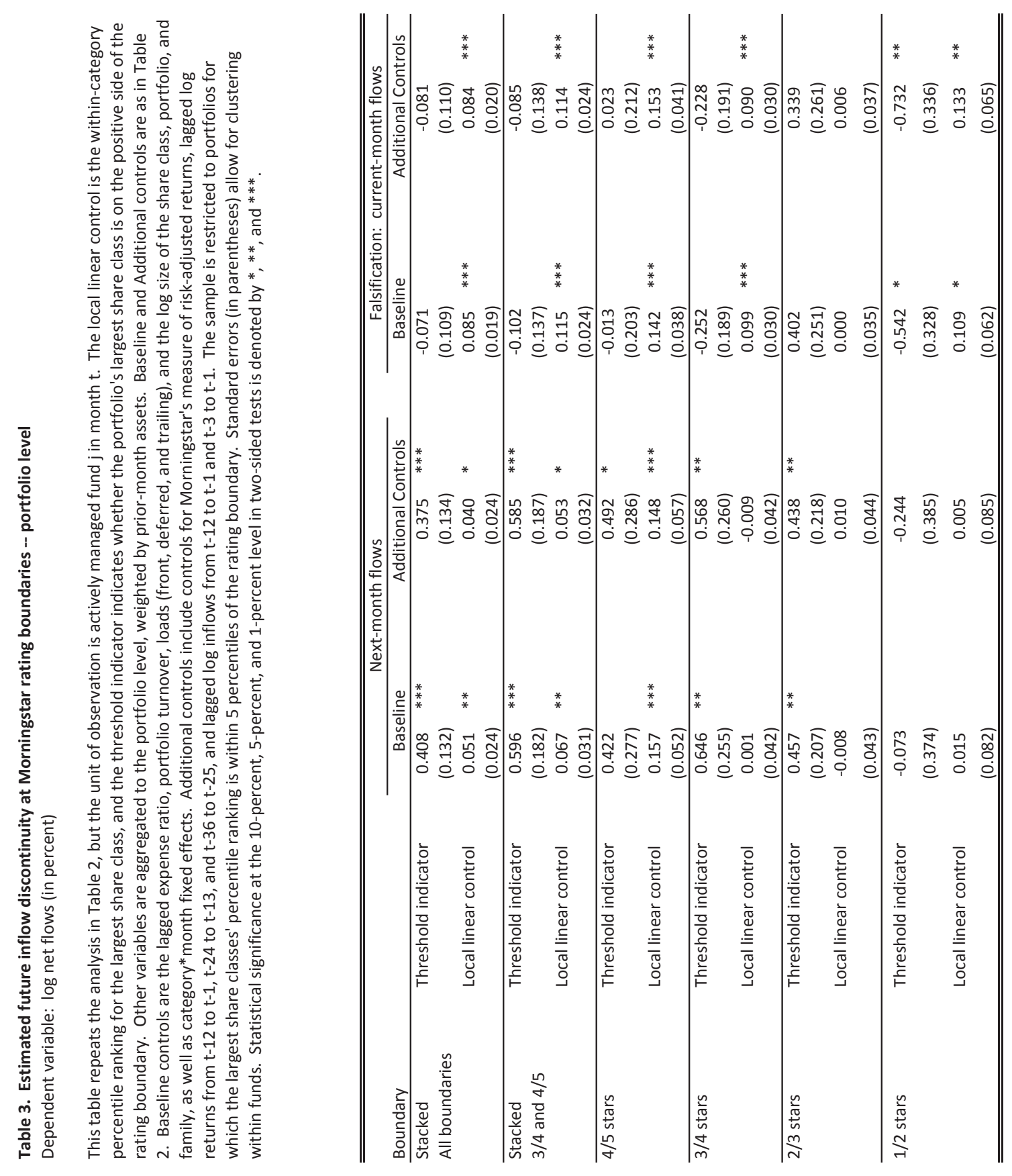
Table 4. Discontinuities in cumulative flows and returns -- portfolio level (all funds)

Dependent variable: log net flows or log net returns (in percentage points)

The table repeats the regressions in Table 3 for different time horizons, for three samples of funds. The overall sample is the same as in Table 3. The dependent variable is the cumulative fund-level log flows or fund-level log returns, calculated either from the ranking month to a future month, or from a past month to the ranking month. As in Table 3, all regressions include the threshold indicator for the 4/5 and 3/4 star boundaries and within-category percentile ranking variables for the largest share class. Regressions include the same controls as in the additional controls specifications in Table 3. "All equity" includes "Large-cap equity", "Mid-cap equity", "Small-cap equity", "Sector funds", and "International equity". "All bonds" includes "Taxable bonds" and "Municipal bonds". "All funds" includes "All equity", "All bonds", and a relatively small number of funds that do not fit into these subsamples, such as balanced and hybrid funds. Standard errors (in parentheses) allow for clustering within funds. Statistical significance at the 10-percent, 5-percent, and 1-percent level in two-sided tests is denoted by * $* *$. and $* * *$.

\begin{tabular}{|c|c|c|c|c|c|c|c|c|c|c|}
\hline \multirow[b]{2}{*}{ Month } & \multicolumn{6}{|c|}{ Flows } & \multicolumn{4}{|c|}{ Returns } \\
\hline & \multicolumn{2}{|c|}{ All funds } & \multicolumn{2}{|c|}{ All equity } & \multicolumn{2}{|c|}{ All bonds } & \multirow{2}{*}{$\frac{\text { All funds }}{0.05}$} & \multirow{2}{*}{$\frac{\text { All equity }}{0.04}$} & \multicolumn{2}{|c|}{ All bonds } \\
\hline \multirow[t]{2}{*}{-12} & -0.83 & & -0.80 & & -0.68 & & & & 0.01 & \\
\hline & $(0.60)$ & & $(0.86)$ & & $(0.86)$ & & (0.09) & $(0.16)$ & $(0.05)$ & \\
\hline \multirow[t]{2}{*}{-9} & -0.69 & & -0.57 & & -0.71 & & -0.01 & -0.01 & -0.01 & \\
\hline & $(0.51)$ & & $(0.75)$ & & $(0.70)$ & & $(0.08)$ & $(0.13)$ & $(0.04)$ & \\
\hline \multirow[t]{2}{*}{-6} & -0.61 & & -0.16 & & -1.25 & $*$ & 0.05 & 0.08 & -0.01 & \\
\hline & $(0.41)$ & & $(0.56)$ & & $(0.66)$ & & $(0.06)$ & $(0.11)$ & $(0.03)$ & \\
\hline \multirow[t]{2}{*}{-3} & -0.46 & $*$ & 0.01 & & -1.00 & $* *$ & 0.03 & 0.06 & -0.02 & \\
\hline & $(0.27)$ & & $(0.35)$ & & (0.49) & & (0.04) & $(0.08)$ & $(0.02)$ & \\
\hline \multirow[t]{2}{*}{0} & -0.09 & & 0.06 & & -0.23 & & 0.01 & 0.02 & -0.02 & $*$ \\
\hline & $(0.14)$ & & $(0.20)$ & & $(0.22)$ & & $(0.02)$ & $(0.04)$ & $(0.01)$ & \\
\hline \multirow[t]{2}{*}{1} & 0.59 & $* * *$ & 0.56 & $* *$ & 0.59 & $* *$ & 0.01 & 0.00 & -0.01 & \\
\hline & (0.19) & & $(0.27)$ & & $(0.27)$ & & $(0.02)$ & (0.05) & $(0.01)$ & \\
\hline \multirow[t]{2}{*}{2} & 0.79 & $* * *$ & 0.89 & $* *$ & 0.66 & $* *$ & 0.05 & 0.07 & -0.01 & \\
\hline & $(0.22)$ & & $(0.37)$ & & $(0.27)$ & & $(0.03)$ & $(0.06)$ & $(0.01)$ & \\
\hline \multirow[t]{2}{*}{3} & 0.87 & $* * *$ & 0.70 & $* *$ & 1.04 & $* * *$ & 0.05 & 0.06 & 0.00 & \\
\hline & $(0.22)$ & & $(0.35)$ & & $(0.28)$ & & $(0.03)$ & $(0.06)$ & $(0.02)$ & \\
\hline \multirow[t]{2}{*}{6} & 1.75 & $* * *$ & 1.93 & $* * *$ & 1.62 & $* * *$ & 0.08 & 0.07 & 0.04 & \\
\hline & (0.39) & & $(0.64)$ & & $(0.47)$ & & $(0.05)$ & (0.09) & $(0.03)$ & \\
\hline \multirow[t]{2}{*}{9} & 2.04 & $* * *$ & 2.19 & $* * *$ & 1.97 & $* * *$ & 0.05 & -0.01 & 0.05 & \\
\hline & (0.51) & & $(0.84)$ & & $(0.60)$ & & (0.07) & $(0.12)$ & $(0.04)$ & \\
\hline \multirow[t]{2}{*}{12} & 2.34 & $* * *$ & 2.35 & $* *$ & 2.32 & $* * *$ & 0.03 & -0.07 & 0.02 & \\
\hline & (0.63) & & $(1.06)$ & & $(0.71)$ & & (0.08) & $(0.15)$ & $(0.04)$ & \\
\hline \multirow[t]{2}{*}{15} & 2.35 & $* * *$ & 2.29 & $*$ & 2.34 & $* * *$ & 0.03 & -0.10 & 0.03 & \\
\hline & $(0.72)$ & & $(1.20)$ & & $(0.82)$ & & (0.09) & $(0.17)$ & $(0.05)$ & \\
\hline \multirow[t]{2}{*}{18} & 2.62 & $* * *$ & 2.33 & $*$ & 2.92 & $* * *$ & 0.02 & -0.12 & 0.03 & \\
\hline & (0.79) & & $(1.34)$ & & $(0.87)$ & & (0.10) & (0.19) & $(0.05)$ & \\
\hline \multirow[t]{2}{*}{21} & 2.81 & $* * *$ & 2.35 & $*$ & 3.21 & $* * *$ & 0.02 & -0.11 & 0.03 & \\
\hline & $(0.86)$ & & $(1.46)$ & & $(0.94)$ & & $(0.11)$ & $(0.20)$ & $(0.06)$ & \\
\hline \multirow[t]{2}{*}{24} & 2.88 & $* * *$ & 2.33 & & 3.46 & $* * *$ & 0.05 & -0.07 & 0.02 & \\
\hline & (0.92) & & $(1.55)$ & & (1.03) & & (0.11) & $(0.21)$ & $(0.06)$ & \\
\hline
\end{tabular}



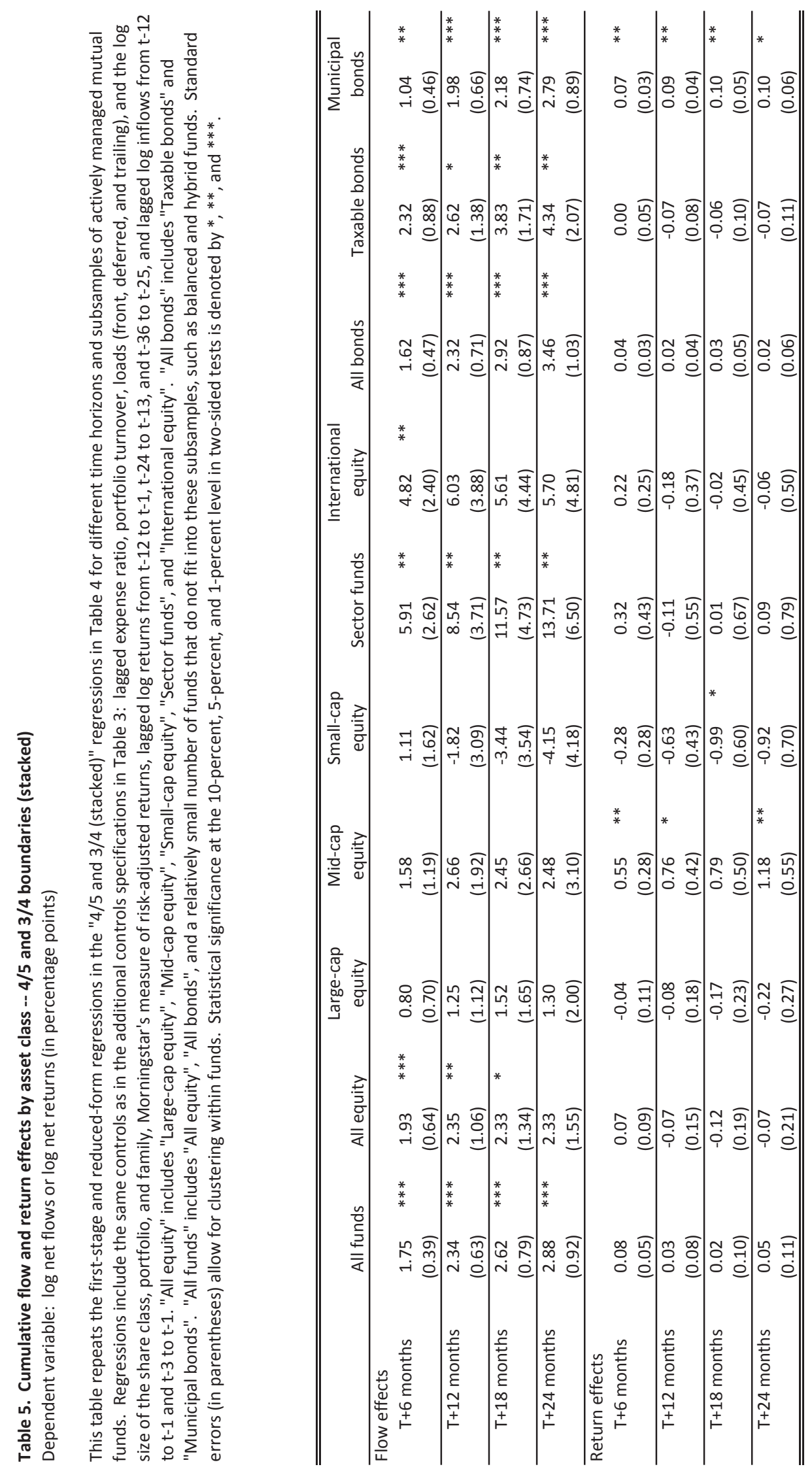


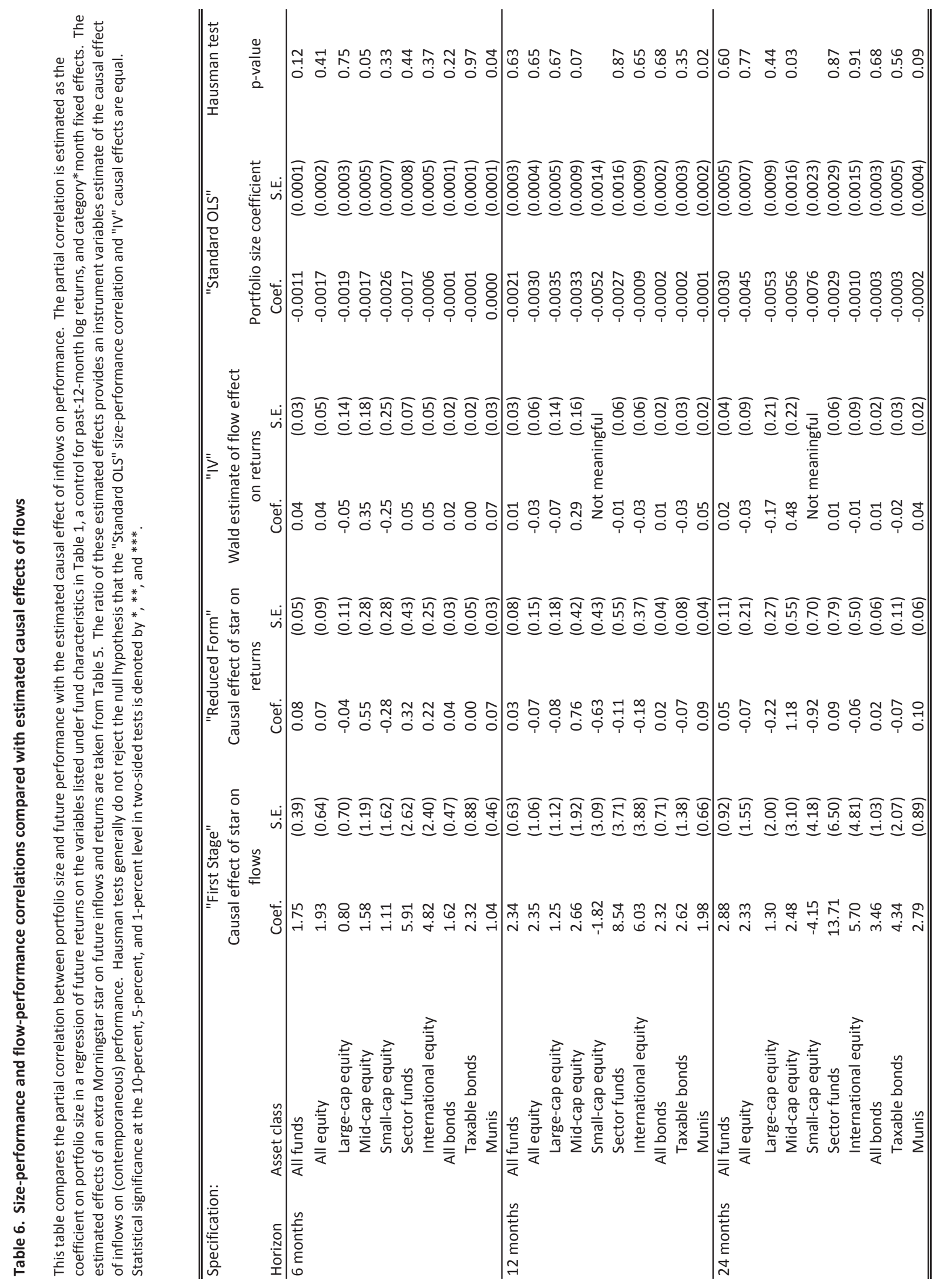



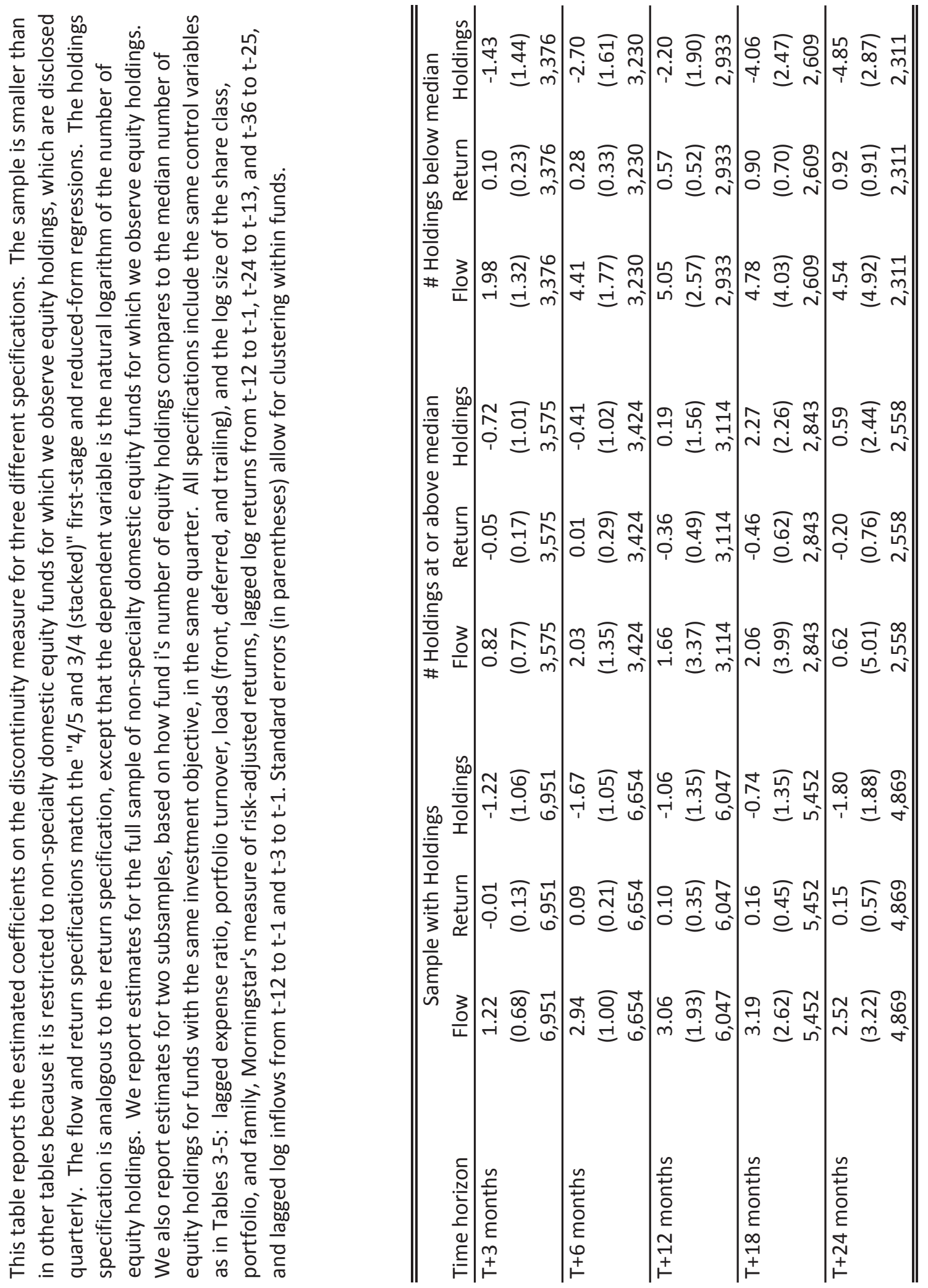


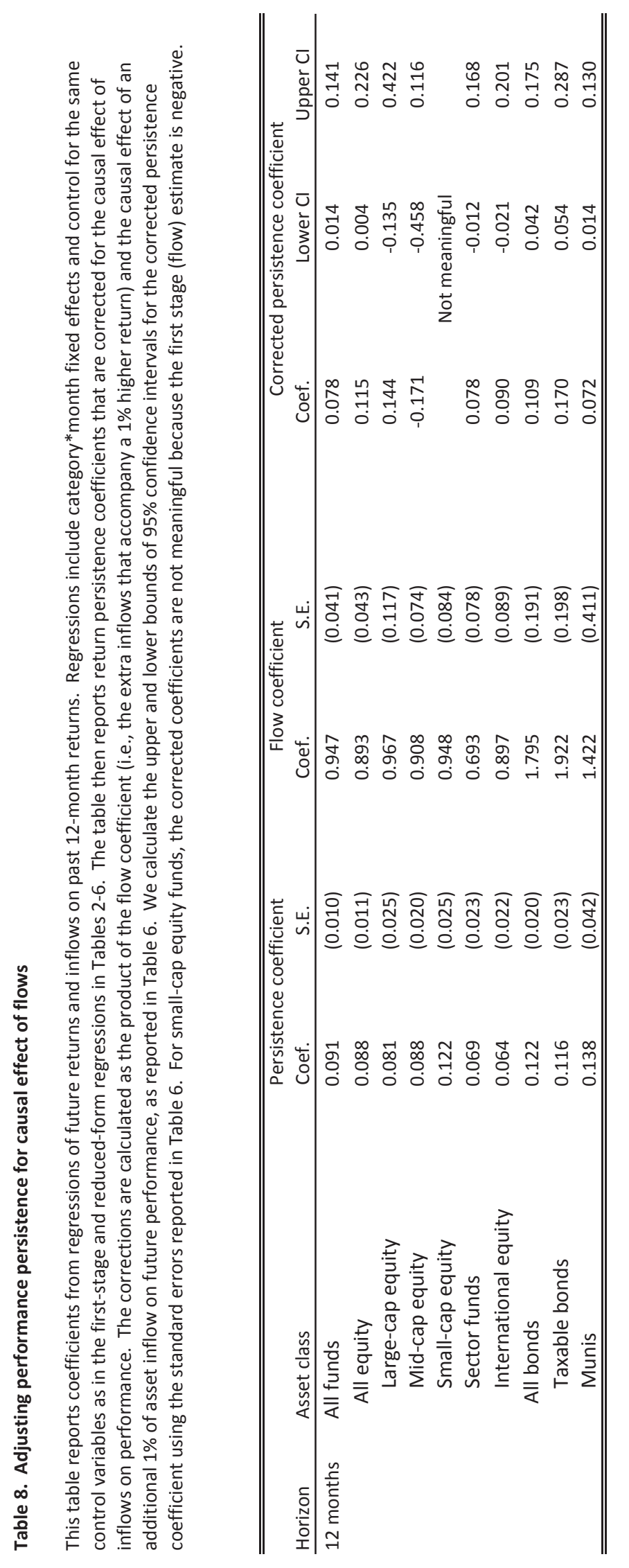




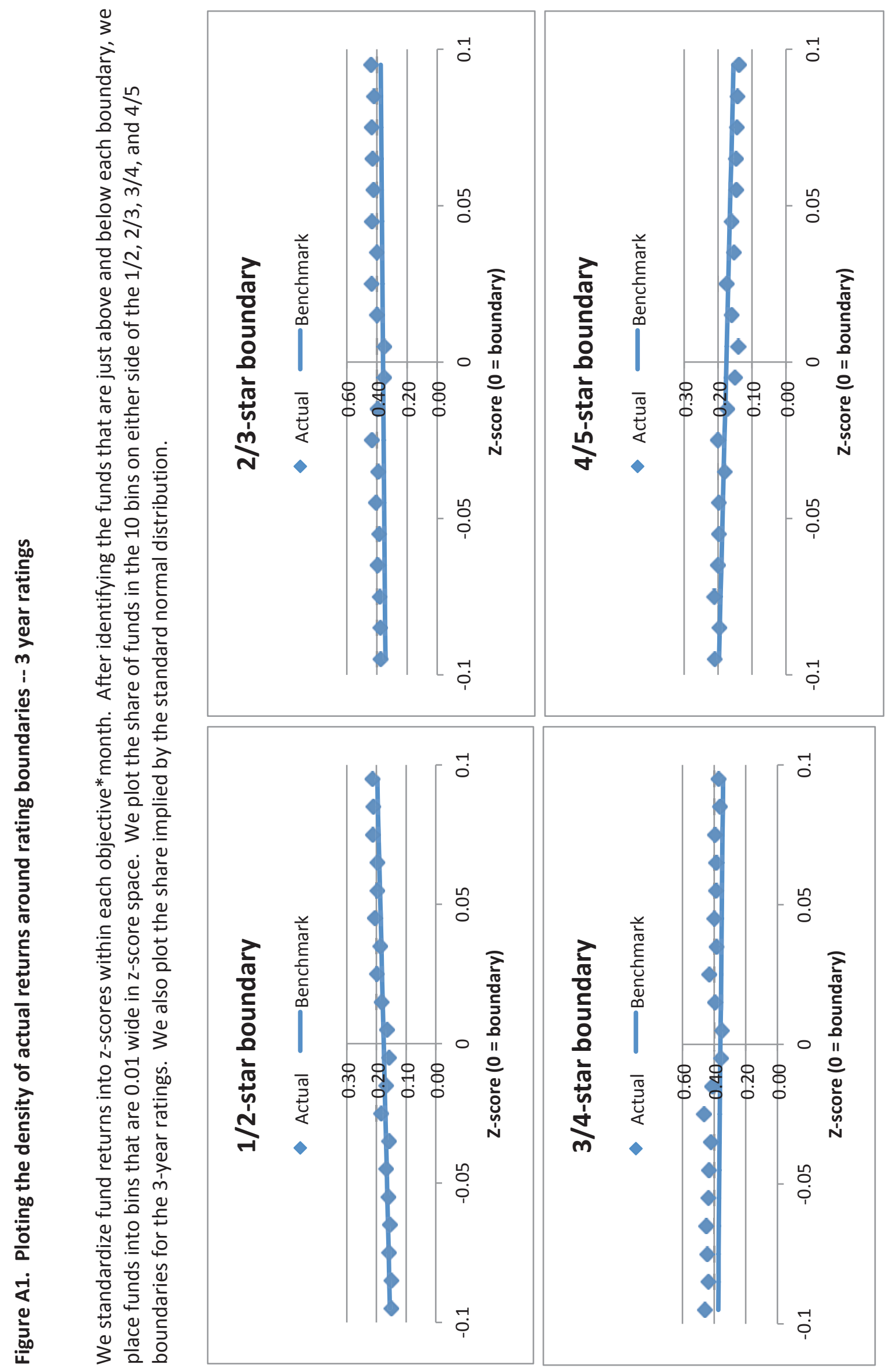




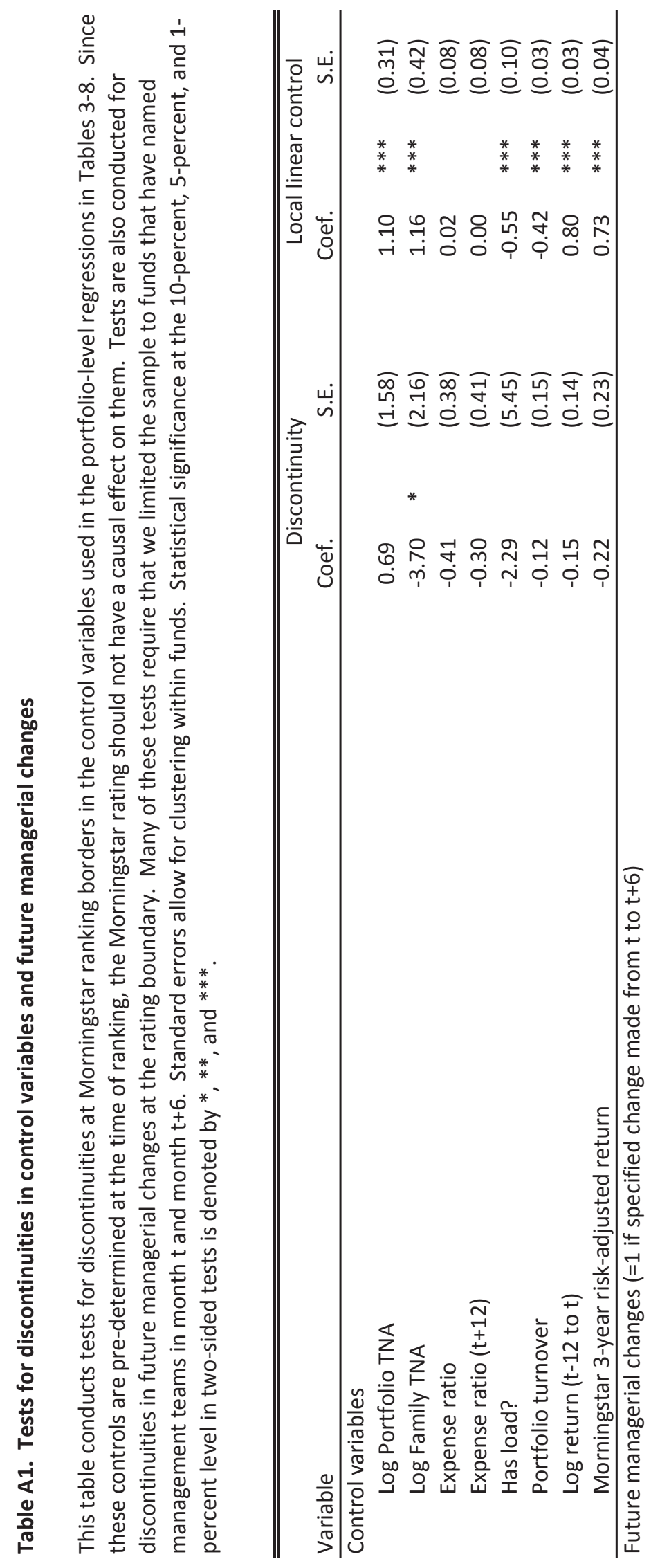


Table A2. Logit regressions predicting future rating

This table reports coefficients from regressions predicting future Morningstar ratings using the same specification as in Tables 3-6. For funds at the boundary between $s$ and $s+1$ stars, the dependent variable is defined as 1 if the fund receives $s+1$ or more stars in the future. Data from all four boundaries are stacked. Regressions with controls include the controls used in Table 3 (both baseline and additional controls).

\begin{tabular}{lccc}
\hline \hline Time horizon & Controls & Discontinuity & Local linear control \\
\hline T+1 month & No & 0.54 & 0.425 \\
& & $(3.41)$ & $(0.007)$ \\
& Yes & 0.56 & 0.499 \\
& & $(5.87)$ & $(0.013)$ \\
\hline T+3 month & No & 0.25 & 0.220 \\
& & $(3.40)$ & $(0.006)$ \\
& Yes & 0.19 & 0.283 \\
& & $(5.81)$ & $(0.012)$ \\
\hline T+6 month & No & 0.13 & 0.119 \\
& & $(3.87)$ & $(0.007)$ \\
& Yes & 0.13 & 0.152 \\
& & $(6.87)$ & $(0.013)$ \\
\hline \hline
\end{tabular}




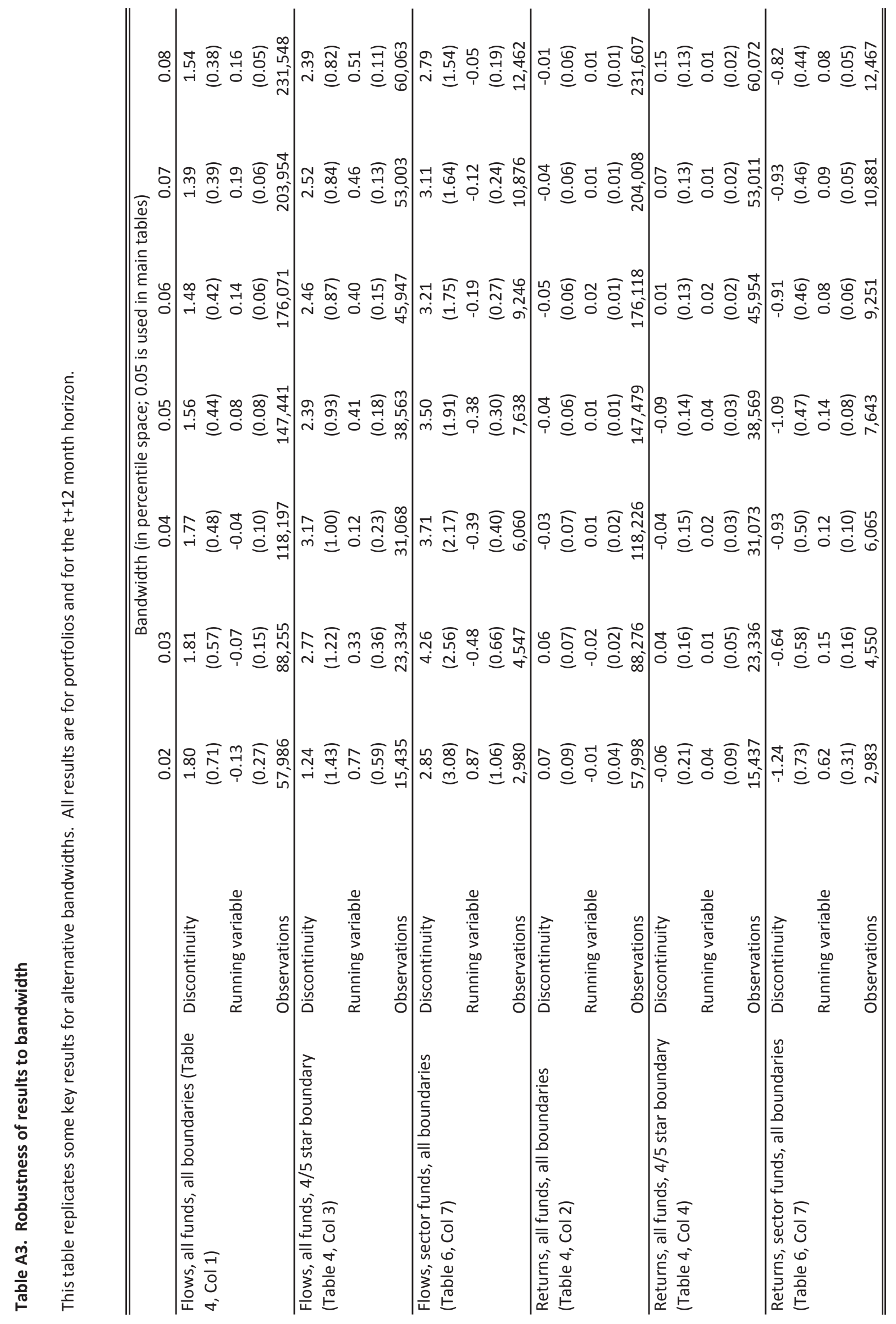




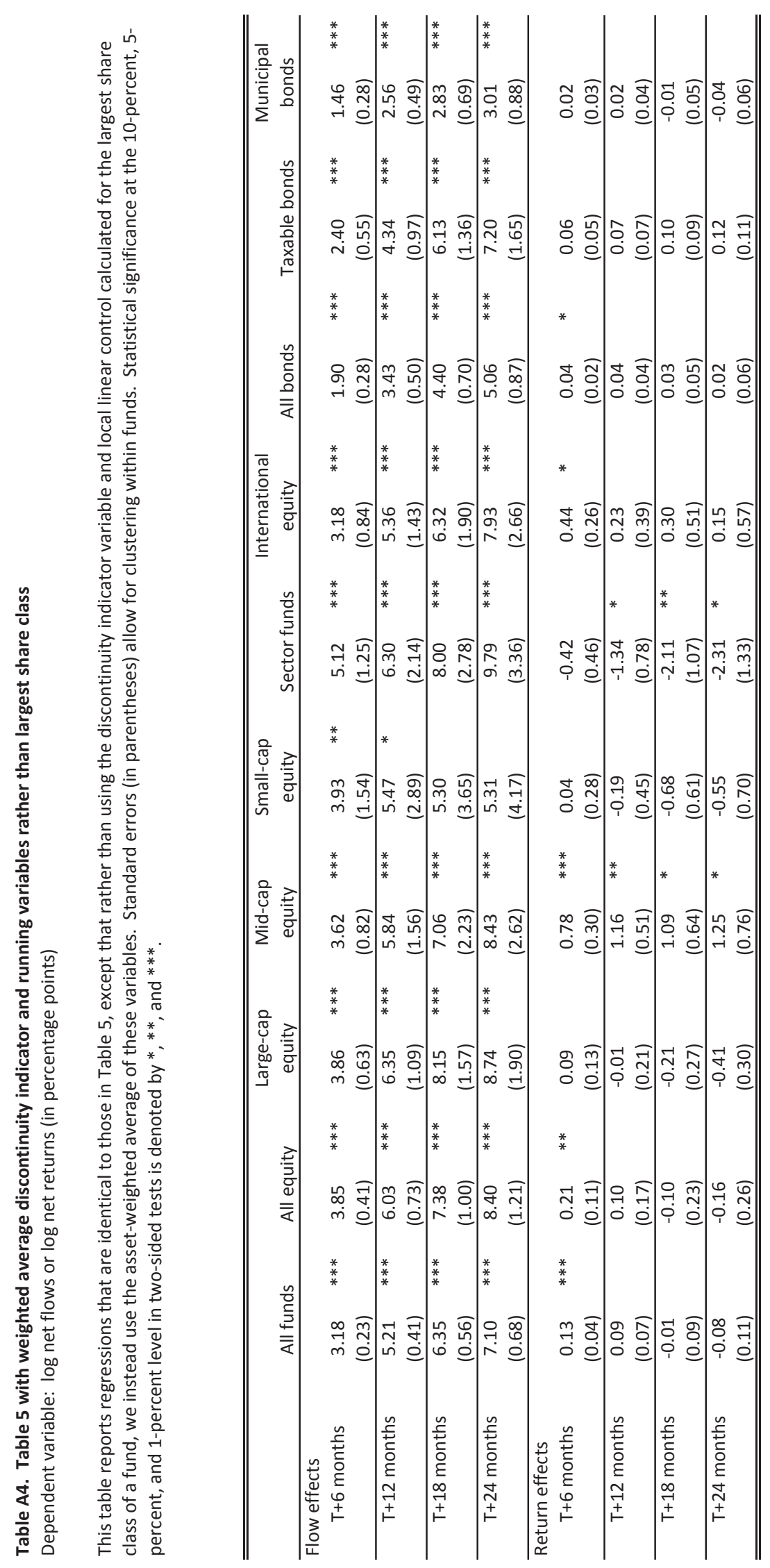




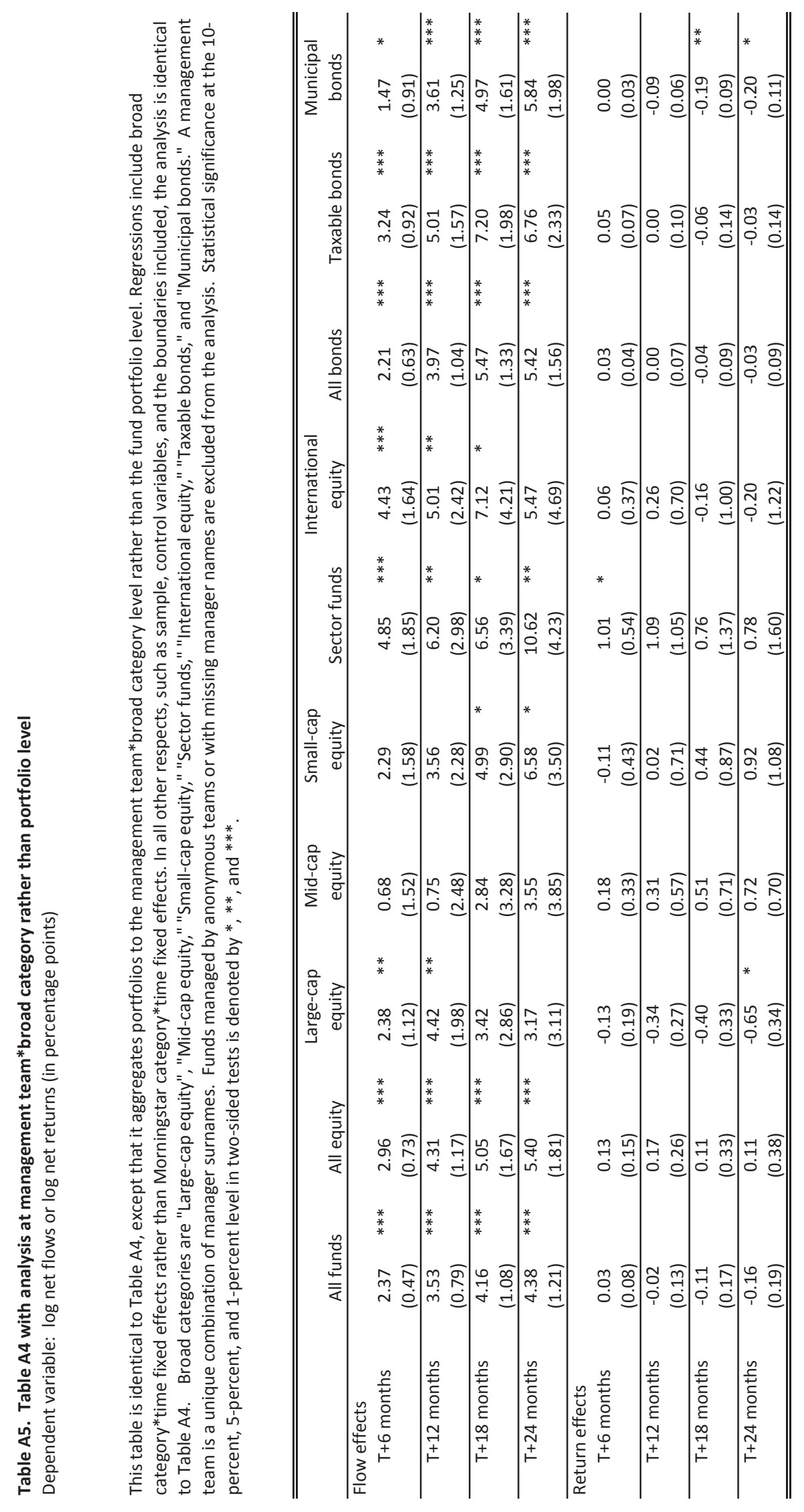




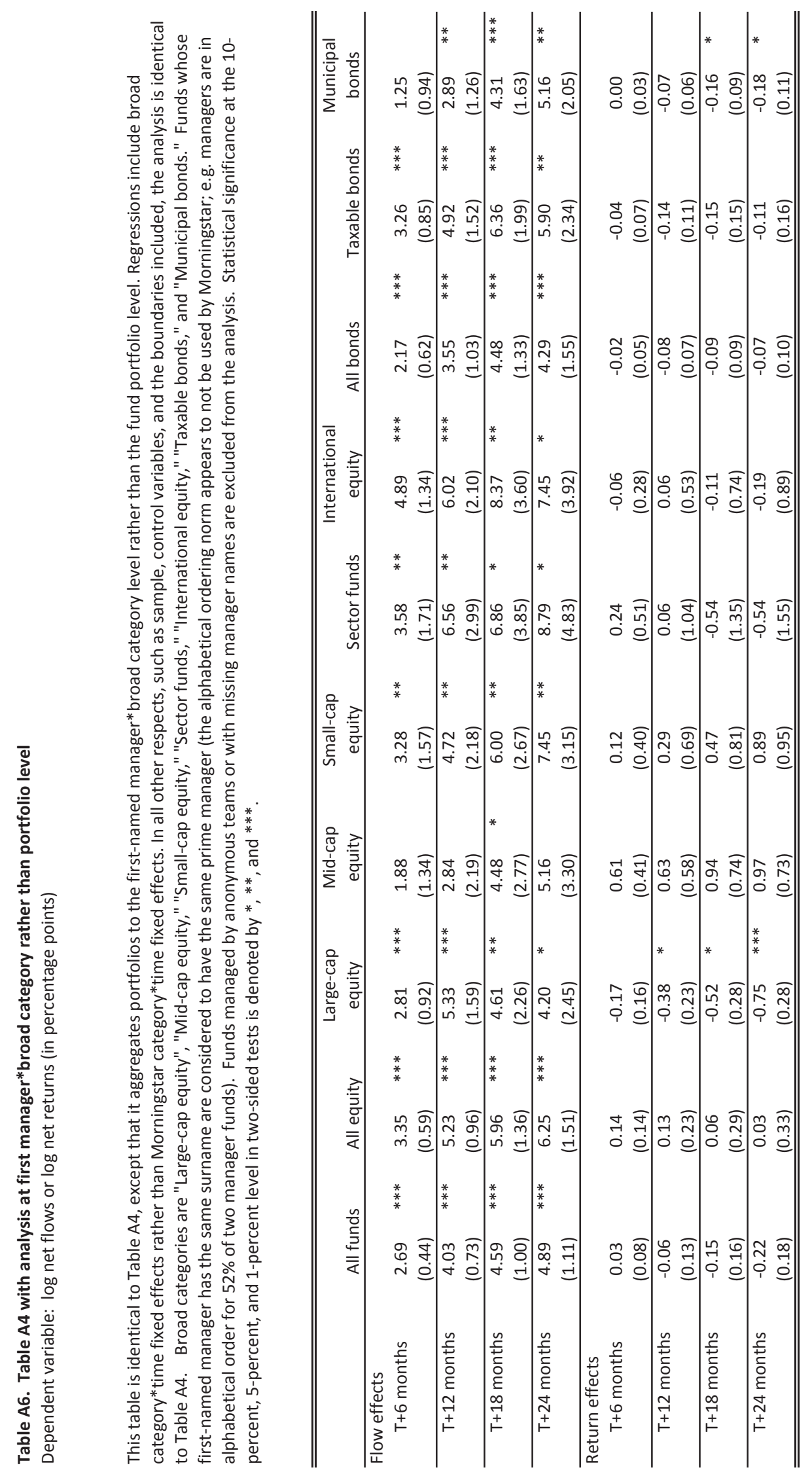




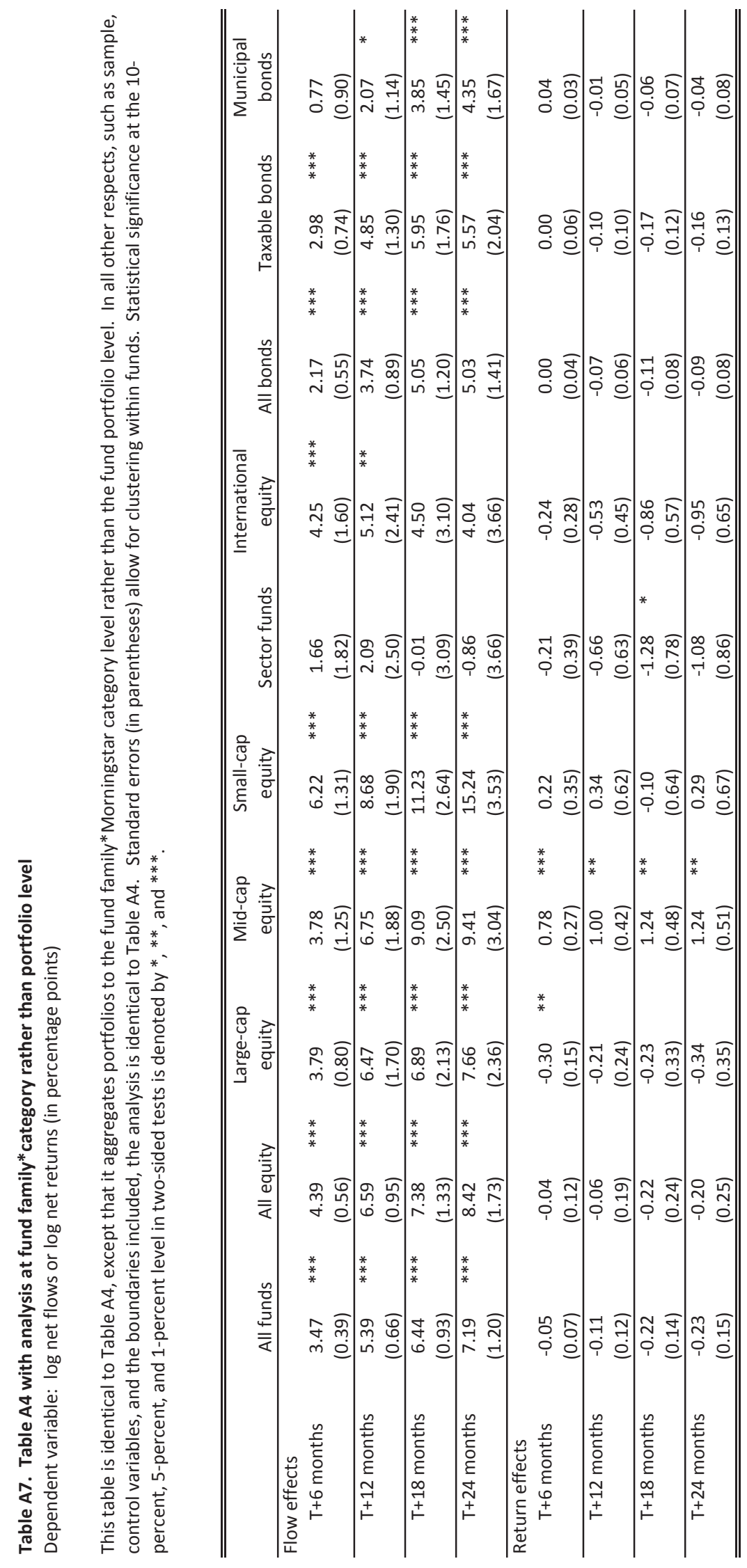




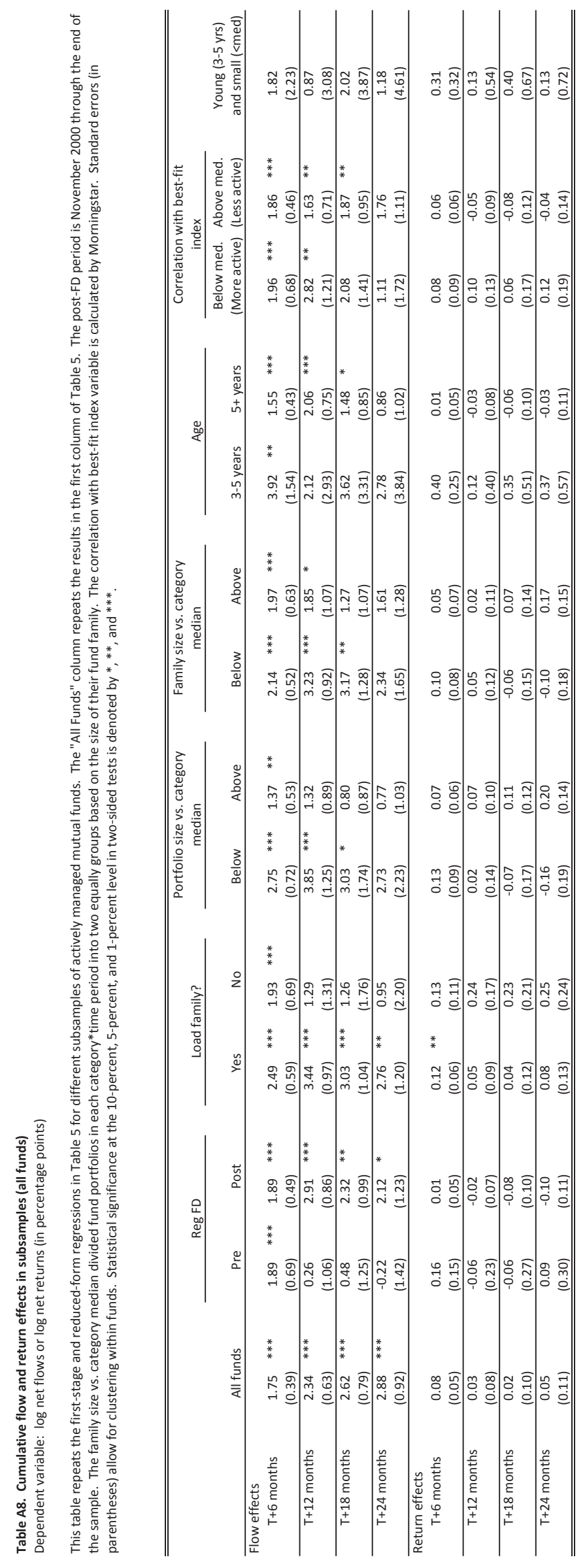




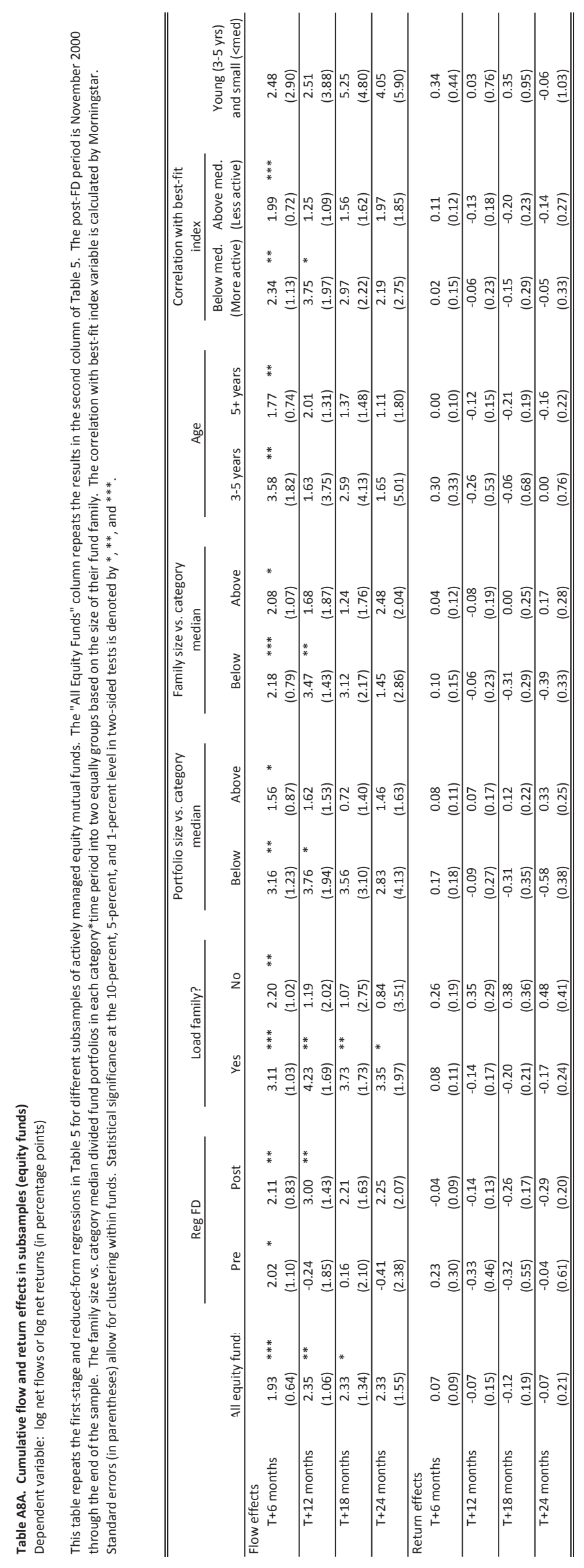




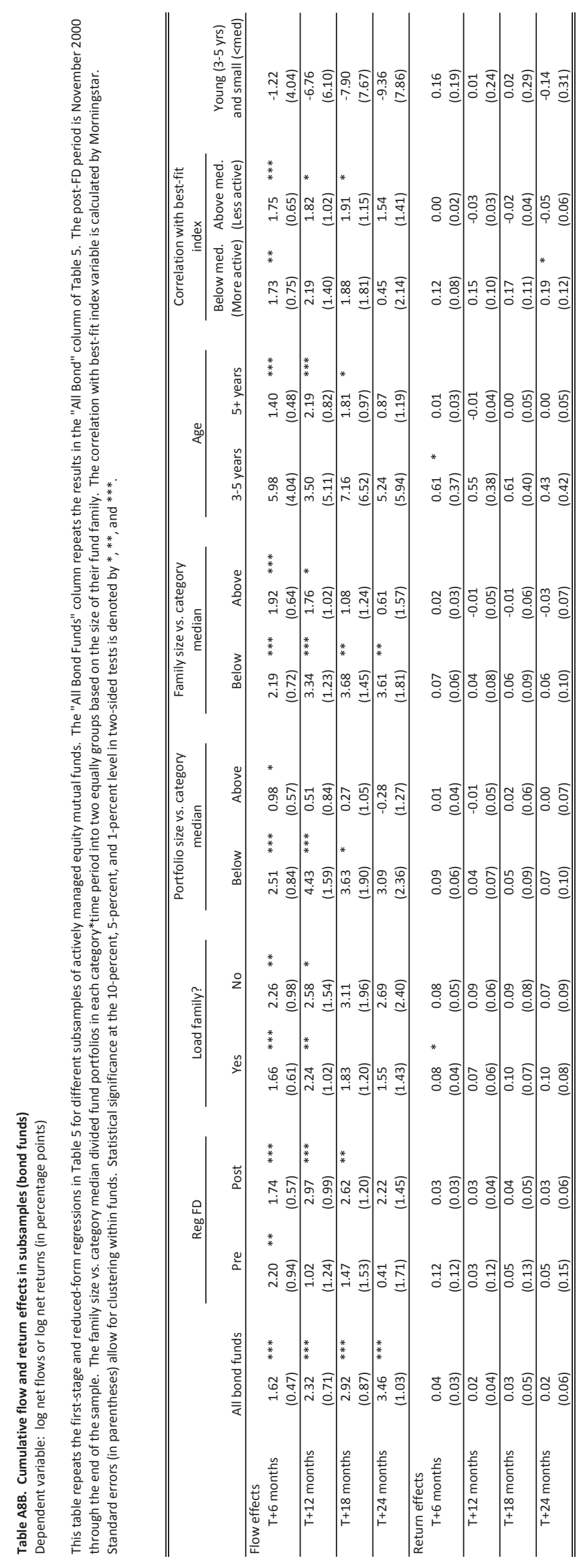

